\title{
Projections of Heat Waves Events in the Intra-Americas Region Using Multimodel Ensemble
}

\author{
Moises Angeles-Malaspina $\mathbb{D}^{1},{ }^{1}$ Jorge E. González-Cruz $\mathbb{D}^{2},{ }^{2}$ and Nazario Ramírez-Beltran ${ }^{3}$ \\ ${ }^{1}$ Mechanical Engineering Department, Polytechnic University of Puerto Rico, San Juan, PR 00918, USA \\ ${ }^{2}$ NOAA-CREST, City College of New York, New York, NY 1031, USA \\ ${ }^{3}$ Department of Industrial Engineering, University of Puerto Rico, Mayagüez, PR 00680, USA
}

Correspondence should be addressed to Jorge E. González-Cruz; jgonzalezcruz@ccny.cuny.edu

Received 22 June 2017; Revised 11 December 2017; Accepted 18 December 2017; Published 22 January 2018

Academic Editor: Annalisa Cherchi

Copyright (C) 2018 Moises Angeles-Malaspina et al. This is an open access article distributed under the Creative Commons Attribution License, which permits unrestricted use, distribution, and reproduction in any medium, provided the original work is properly cited.

\begin{abstract}
Significant accelerated warming of the Sea Surface Temperature of $0.15^{\circ} \mathrm{C}$ per decade (1982-2012) was recently detected, which motivated the research for the present consequences and future projections on the heat index and heat waves in the intra-Americas region. Present records every six hours are retrieved from NCEP reanalysis (1948-2015) to calculate heat waves changes. Heat index intensification has been detected in the region since 1998 and driven by surface pressure changes, sinking air enhancement, and warm/weaker cold advection. This regional warmer atmosphere leads to heat waves intensification with changes in both frequency and maximum amplitude distribution. Future projections using a multimodel ensemble mean for five global circulation models were used to project heat waves in the future under two scenarios: RCP4.5 and RCP8.5. Massive heat waves events were projected at the end of the 21st century, particularly in the RCP8.5 scenario. Consequently, the regional climate change in the current time and in the future will require special attention to mitigate the more intense and frequent heat waves impacts on human health, countries' economies, and energy demands in the IAR.
\end{abstract}

\section{Introduction}

The intra-American region encompasses Northern South America, Central America, Gulf of Mexico, the Caribbean region, and the Western Atlantic [1-3], where a complex interaction among synoptic atmospheric/oceanic patterns drives the rainfall activity in the region [4-7] (see Figure 1(a)).

In tropical regions, the Sea Surface Temperature (SST) is one of the variables that drive rainfall, with a weak impact when SST is less than $26^{\circ} \mathrm{C}$ and a stronger effect when SST is between $26^{\circ} \mathrm{C}$ and $29.5^{\circ} \mathrm{C}$. The relationship between SST and rainfall is not linear, so precipitation tends to decrease when SST is greater than $29.5^{\circ} \mathrm{C}$ [8]. Consequently, SST modulates the intra-Americas region (IAR) rainfall development from May to July, while in the next months the vertical wind shear (VWS) impacts the thermal vertical convection and cyclogenesis activity $[5,9,10]$. An additional variable in the IAR is the Bermuda-Azores high-pressure system (one pole of the North Atlantic Oscillation Index, NAO) which interacts with the Caribbean low-level jet, causing a downward dry air, hindering precipitation, and warming the surface $[4$, 11, 12]. A direct consequence of the high-pressure system oscillation is the development of stronger/weaker easterly winds causing cooler/warmer SST leading to a drier/wetter region $[4,13,14]$. This relationship is known as the windevaporation-SST feedback pointing out a direct relationship among wind speed, evaporation, and sea level pressure (SLP) [15]. Furthermore, a deep subsidence from Central America to the Caribbean region could play an additional role in the IAR rainfall activity $[4,16]$. Moreover, Saharan dust episodes from June to August are likely to generate a rainfall deficit due to aerosol interaction with cloud condensation nuclei and dry air coming from the northwest African desert [17]. These complex relationships lead to a bimodal rainfall pattern in the IAR during the rainy season $[4,5,18-21]$. This rainy season is divided into the Early Rainfall Season (ERS) defined from April to July (which contains the first rainfall peak) and the Late Rainfall Season (LRS) from August to November, 


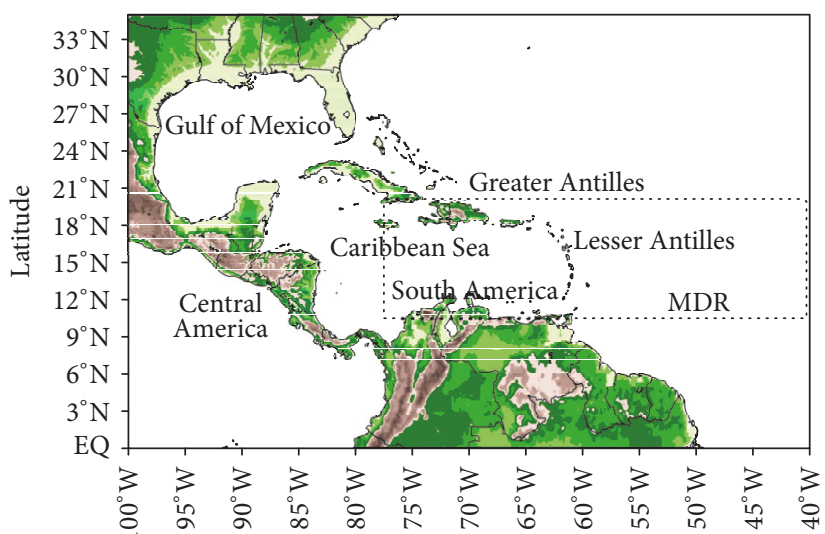

Intra-American region Longitude

\begin{tabular}{|c|c|c|c|c|c|c|c|c|c|c|c|}
\hline & 1 & 1 & 1 & 1 & 1 & $\perp$ & $\perp$ & $\perp$ & $\perp$ & & \\
\hline 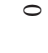 & 오 & $\stackrel{8}{ }$ & 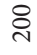 & ¿ & ஓ & ஓু & ᄋ & $\begin{array}{l}8 \\
0 \\
10\end{array}$ & ঠ & $\begin{array}{l}8 \\
\stackrel{0}{10}\end{array}$ & ঠి \\
\hline
\end{tabular}

(a)

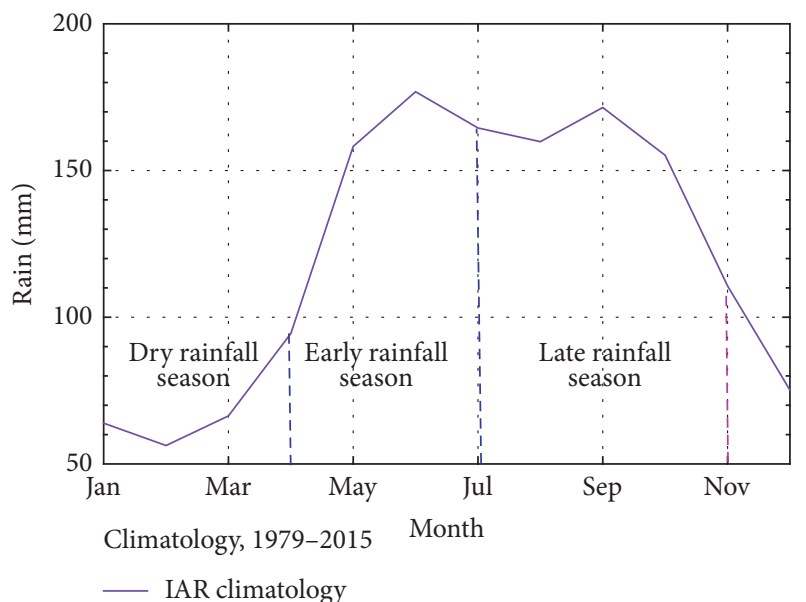

(b)

FIGURE 1: (a) Major areas in the IAR; (b) IAR rainfall bimodal nature showing the DS, ERS, and LRS. The dry season is defined from December to March, corresponding to the season with the lowest rainfall intensity events.

holding the second rainfall peak. In addition, a dry season (DS) is defined between December and March where the lowest rainfall intensity events are observed (see Figure 1(b)).

IAR warming was recently detected with an annual SST increase of $0.016^{\circ} \mathrm{C}$ per year in the ERS, while in the LRS an SST increase of $0.021^{\circ} \mathrm{C}$ per year was observed [6]. This regional warming could disrupt the synoptic atmospheric and oceanic patterns. A warmer region increases the nearsurface air temperature and intensify evaporation from the sea, enhancing moisture content in the atmosphere and driving the relative humidity $(\mathrm{RH})$ change. In these conditions, extreme events such as HWs could intensify.

Air temperature and $\mathrm{RH}$ are key variables to calculate the heat index (HI), which is used to define HWs events. In addition, different regions across the world have a unique temperature and $\mathrm{RH}$ climatology causing several heat waves (HWs) definitions [22] such as in Europe where a heat wave is defined as at least six consecutive days with daily maximum air temperature greater than the relative threshold of the 90 th percentile [23]. A more complex definition was applied to whole Europe and the United States (US) using at least three consecutive days with daily maximum temperature and average maximum temperature above the 97.5th percentile [24]. The heat waves were estimated using the National Centers for Environmental Prediction (NCEP) reanalysis data for the present time and the Parallel Climate Model for future projections using the business-as-usual scenario. Percentile was applied to daily data from 1961 to 1990 for reanalysis data and 2080-2099 for GCMs outputs [24]. On the other hand, a heat wave magnitude index (HWMI) was developed to analyze HWs across Earth regions including Europe, United States, Greece, and Russia [25, 26]. These researchers selected NCEP reanalysis and ERA-Interim (ERA-I) reanalysis datasets, upscaling ERA-I to the NCEP resolution. Additionally, they defined a HWMI as the maximum magnitude of heat waves in a year, where the heat wave was defined as at least three consecutive days with daily maximum temperature greater than the 90th percentile and centered in a 31-day moving window $[25,26]$. On the other hand, other $\mathrm{HW}$ definitions were developed as at least two consecutive days with daily mean temperature greater than the 95th percentile (calculated with daily data for 28 years) providing the highest HWs occurrence frequency in the Northwest United States $[27,28]$. Furthermore, in Southern US, a heat wave was defined as at least two consecutive days with daily maximum and minimum HI above the relative threshold of the 99th percentile [29]. Percentile was obtained from 39 years of daily data. Moreover, the US National Weather Service (NWS) has defined the heat waves events as at least three consecutive days with daily maximum temperature greater than the absolute threshold of $32^{\circ} \mathrm{C}$ [30]. Although this criterion is widely used, it does not capture the HWs events at different regions. This way, in the US regions with high $\mathrm{RH}$ (northeast region), a heat wave is defined as at least three consecutive days with temperature at or above $32.2^{\circ} \mathrm{C}[22]$.

During the past decade, a connection between climate change and heat waves intensity-frequency alterations was identified, even causing more death than all other extreme events together in the US such as hurricanes, floods, and tornadoes. In the Eastern and Western US, a 20\% HWs number increase was observed from 1949 to 1995, while from 1999 to 2003, 688 deaths per year were registered, primarily due to extreme hot day events [31]. In the city of Chicago, HWs impact on human health caused 800 deaths in the year 1995 [30]. These hot day events were determined using the NWS definition. The mortality risks in 43 US cities were investigated from 1987 to 2005. A heat wave mortality risk increase of $2.49 \%$ for every $1^{\circ} \mathrm{F}$ heat wave intensity and $0.38 \%$ for every one day where the heat wave duration increases was found [27]. In this case, the HW was 
defined using mean temperature and the 95th percentile as threshold.

Additional factors contributing to heat waves events are fast urban growth and the urban heat island (UHI) which increase the daytime air temperature $\left(1^{\circ} \mathrm{C}-6^{\circ} \mathrm{C}\right)$ as well as the nighttime temperature [31]. As a consequence, the UHI intensifies heat waves events affecting elderly population and communities without air conditioning systems [32, 33].

Heat waves analyses in the tropical region and particularly in the IAR region are very scarce. One of the few cases studied is the two hottest summers registered in the Island of Puerto Rico (2012 and 2013). In these events, a strong surface high-pressure system was located in the Northeast Atlantic Ocean causing high mortality related to high air temperature and heat stroke $[34,35]$. In addition, heat index vulnerability was developed for San Juan Bay estuary in Puerto Rico, where high vulnerability areas correspond to urban zones with a high concentration of elderly and unemployed populations [36]. Furthermore, a research agenda for the IAR was proposed to mitigate the extreme heat impact on the community residents. The development of a study program is expected in the near future to mitigate and adapt to climate changes [37]. On the other hand, a recent work pointed out a heat index increasing trend of $0.05^{\circ} \mathrm{C} / \mathrm{yr}$ in Mesoamerica and the Caribbean Sea (MAC) and the Caribbean Islands. The authors used NCEP reanalysis and weather station data from 1980 to 2014. Additionally, they found 45 heat wave events in the period of study with $82 \%$ of these events with a duration of 2-2.5 days [22].

Future global warming due to anthropogenic activities is likely to enhance HW events, becoming more intense and frequent and with longer duration [24, 38]. Several General Circulation Models (GCMs) were used to calculate a multimodel ensemble for daily maximum air temperature along the 21st century. A global mean HWMI increase was projected by these models. Furthermore, they show intense heat wave magnitude in Southern US, Central America, and Northern South America, especially in the end of the 21st century, but without capturing events in the Caribbean [26]. In addition, heat waves projection was performed in other regions. For instance, for Australia, an annual death increase of $50 \%$ was projected due to heat stroke in the year 2050 [33]. Chicago may experience increases of $25 \%$ of $\mathrm{HW}$ events, while Paris may experience a $31 \%$ increase in the last 20 years of the 21st century. These projections were obtained using the Parallel Climate Model (PCM) under the business-as-usual scenario [24]. In addition, Los Angeles forecast's future HWs number will increase (12 to 70 ) during the climate period 2070-2099 [31], while fast heat waves duration and frequency change were detected in North America in the early decades of the 21st century [39]. In Europe, HW events were projected under the AlB Intergovernmental Panel on Climate Change (IPCC) scenario, showing a frequency increase to 40 days (2075-2094) and amplitude intensification up to $7^{\circ} \mathrm{C}$ per day [40]. On the other hand, heat waves projection in the IAR and the Caribbean region is very scarce, but it is expected to be as vulnerable as high latitudes regions due to intense hot day events [32].
Based on the literature, a changing climate may lead to extreme events such as heat waves; consequently, this work attempts to assess the likely repercussions of IAR warming on HWs frequency and intensity in the present and in the future following the IPCC Representative Concentration Pathway (RCP) 4.5 and RCP8.5 scenarios. Hence, the fundamental question this work attempts to answer is how extreme heat waves events may change in a warmer 21st century in the IAR.

In the next sections, this article is organized as follows. Reanalysis data and the GCMs description will be presented along with the methodology to calculate HI and HWs. Posteriorly, the current climatology and climate disruption are analyzed. In the next section, heat waves events' changes in frequency and intensity are related to the regional warming. Finally, future projections using GCMs are studied to accomplish the main goals of this research.

\section{Methodology}

In this section, the observed reanalysis data and GCMs used to project heat waves along the 21st century are described. Posteriorly, heat index and heat wave definitions are explained. The nonparametric Mann-Kendall test was chosen to assess trends in both current and future time series projections. Furthermore, the IPCC scenarios are described as the baseline for numerical experiments.

2.1. Reanalysis Data. The National Centers for Environmental Prediction (NCEP) reanalysis data from 1948 to 2015 and at 2.5 degrees of resolution was selected to calculate the IAR climatology and to determine changes in extreme events such as HWs. This dataset has been widely used to analyze atmospheric events at synoptic scales. In the Caribbean region, the NCEP data was used to analyze the North Atlantic Oscillation Index and the ENSO impact on the rainfall generation $[9,18,19,41-43]$. In a similar way, NCEP data was used to study the low-level wind/divergent anomalies, the vertical wind shear, the sea level pressure, the circulation belt between Central America and the Greater Antilles, and the high-pressure system relationship with summer dry events in this region (low rainfall in the month of July) $[4,5,9,10$, $13,19,44]$. Furthermore, NCEP reanalysis was the baseline to study the HWMI across Europe, Greece, and Russia, among other regions [26]. Consequently, this dataset was selected to be representative of the whole intra-Americas region and to link heat waves events with large-scale phenomena to identify possible synoptic atmospheric variables driving these hot day events.

The relevant NCEP atmospheric fields in this work comprise the surface air temperature $\left({ }^{\circ} \mathrm{C}\right)$ and relative humidity (\%) at $0,6,12$, and 18 hours in the universal time coordinate (UTC). In the Caribbean region at this time interval, the maximum air temperature could correspond to 18 UTC. This maximum air temperature is relevant in this work because it provides the maximum HI per day used in the HW definition. For instance, in Puerto Rico, the 18 UTC time corresponds to 2 p.m., while 12 UTC time is far away from the expected maximum temperature. Consequently, one maximum $\mathrm{HI}$ value per day is calculated at 18 UTC. 
In addition, monthly surface air temperature and meridional and zonal winds at $850 \mathrm{mbar}$ level $(\mathrm{m} / \mathrm{s})$ are retrieved to compute warm/cold advection. This advection is calculated as the dot product between the air temperature gradient $(\vec{\nabla} T)$ and the wind velocity $(\vec{V})$ expressed in the equation $\partial T / \partial t+\vec{V} \cdot \vec{\nabla} T=0$ in cylindrical coordinates with an Earth radius of $6.37 \times 10^{6}$ meters. Vertical Omega velocity and $\mathrm{RH}$ from 1000 to 300 mbar meridionally averaged between $8.5^{\circ} \mathrm{N}$ and $16^{\circ} \mathrm{N}$ are used to determine vertical atmosphere structures. This vertical air motion is expressed by means of the pressure rate of change for an air parcel, in $\mathrm{Pa} / \mathrm{s}$, and represents the vertical velocity at a synoptic scale assuming hydrostatic equilibrium. Positive values represent sinking air, while negative values mean rising air. In addition, sinking dry air could play a significant role in surface warming. On the other hand, the dataset is divided into two climate periods. The first one is defined from 1948 to 1998, and the second climate period is defined from 1999 to 2015. The year 1998 was selected because this year depicts the beginning of an accelerated climate change in the IAR region as it will be explained in Section 4 of this article.

2.2. IPCC Scenarios. The third and fifth reports of the IPCC have related the global warming to the $\mathrm{CO}_{2}$ increase attributed mostly to the burning of fossil fuels [38, 45]. Furthermore, rawinsonde and satellites measurements showed that the troposphere and the Earth surface have been warming [45]. In consequence, the IPCC has developed a series of scenarios to project likely future impacts of the human activity on the global warming. The old scenarios IS92 and SRES [46] have been updated to the third generation of scenarios called representative concentration pathways. The RCPs are composed of four different $\mathrm{CO}_{2}$ emissions and radiative forcing. The lowest forcing scenario RCP2.6 projects an anthropogenic total $\mathrm{CO}_{2}$ emission of $9.97 \mathrm{PgC} / \mathrm{yr}$ in 2020 and a radiative forcing peak of $490 \mathrm{CO}_{2}$-eq by midcentury to decline later. The intermedia scenario RCP4.5 represents a maximum total $\mathrm{CO}_{2}$ emission in the year 2050

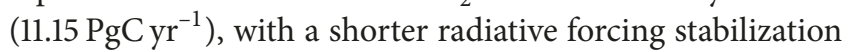
after 2100 (650 $\mathrm{CO}_{2}$-eq), while the scenario RCP6.0 stabilizes shortly after 2100 with $850 \mathrm{CO}_{2}$-eq and a maximum $\mathrm{CO}_{2}$ emission in the year $2080\left(17.07 \mathrm{PgC} \mathrm{yr}^{-1}\right)$. The business-asusual scenario RCP8.5 describes a nonstop $\mathrm{CO}_{2}$ emission and a permanent radiative forcing increase with a value of $1370 \mathrm{CO}_{2}$-eq in 2100 [45, 47]. The scenarios RCP4.5 and RCP8.5 were selected in this research to quantify the impact of the likelihood of the global average surface temperatures to exceed between 2 and 4 degrees Celsius at the end of the 21st century.

2.3. General Circulation Models: CMIP5 Project. The fifth phase of the Coupled Model Intercomparison Project (CMPI5) affords a set of climate simulations to evaluate past and future climate change, where long-term simulations are made available for climate responses to changing atmospheric composition and land cover $[48,49]$. In this study, five GCMs were selected to calculate future daily maximum HI. GCMs provide atmospheric data every 3 hours at $0,3,6,9,12,15,18$, and 21 UTC and overlapping with NCEP dataset at 6, 12, and 18 UTC. In consequence, in this study, GCMs outputs were resampled to the same NCEP time resolution $(0 \mathrm{~h}, 6 \mathrm{~h}, 12 \mathrm{~h}$, and $18 \mathrm{~h}$ ) to have the air temperature and relative humidity at the same matched time period. The maximum air temperature used to calculate the daily maximum HI corresponds to 18 UTC, which, for instance, for the Island of Puerto Rico corresponds to 2:00 p.m. We consider it as representative of the region. On the other hand, GCMs with three-hourly data outputs are very scarce, but we found five models. They are the Community Climate System Model version 4 (CCSM4), with a resolution of $0.9 \times 1.25$ degrees in latitude and longitude, respectively; the Centre National de Recherches Météorologiques Coupled Models version 5 (CNRM-CM5), with $1.4 \times 1.4$ degrees of resolution; NOAA Geophysical Fluid Dynamics Laboratory Climate Model version 3 (GFDL-CM3) with $2.0 \times 2.5$ degrees; Model for Interdisciplinary Research on Climate-Earth System Model (MIROC-ESM) with 2.79 $\times 2.81$ degrees; and the Meteorological Research InstituteCoupled Atmosphere-Ocean GCM (MRI-CGCM3) at 1.11 $\times 1.125$ degrees of resolution. Currently, CCSM4 is one of the state-of-the-art global numerical models with the finest resolution in latitude, while the model MRI-CGCM3 has the finest resolution in longitude. Additional models were chosen because they provide 3-hourly output data. On the other hand, mesoscale models such as the Regional Atmospheric Model System (RAMS) or the Weather Research and Forecasting Model (WRF) afford high resolution but with a very expensive computational cost (there is no output dataset available in the IAR).

These GCM models do not provide RH data; thereby, the $\mathrm{RH}$ is calculated every 3 hours using the surface air temperature, surface pressure, and specific humidity ( $\mathrm{SH}$ ). The $\mathrm{SH}$ allows calculating the vapor mass mixing ratio, while the surface pressure allows calculating the vapor pressure. Finally, the RH is obtained using the Clausius-Clapeyron equation for saturated vapor pressure [50-52]. In addition, these GCM data are distributed into two climate periods: the first one is called the "first future climate period" from 2026 to 2045 , while the second dataset is called the "second future climate period" from 2081 to 2100.

2.4. Heat Index and Heat Waves. Heat index is an apparent temperature in function of air temperature and $\mathrm{RH}$ estimated from a complex body's heat transfer balance [53] and represents a measure of heat-stress danger [54]. The HI is calculated using the methodology developed by NOAA's National Weather Service and using Rothfusz's regression with an error of $1.3^{\circ} \mathrm{F}$ [55]. This regression is adjusted according to the temperature and $\mathrm{RH}$ ranges $[56,57]$. Furthermore, an excessive environmental heat is ruled by days with extremely high HI. This event is defined as HWs when a prolonged period of high-pressure system leads to excessively hotter days with high humidity.

In humid regions, heat waves calculated with air temperature underestimate the $\mathrm{HW}$ intensity, making it essential to use an apparent temperature to account for the heat wave 
amplification due to high humidity [58]. The intra-Americas region, particularly the Caribbean, is characterized by intense $\mathrm{RH}$ as well as high air temperature along the entire year. Consequently, in this region, the heat index is a good alternative to account for humidity impact on heat wave intensity. In addition, people's adaptation to this warm environment requires defining a relative threshold instead of an absolute threshold [59]. This relative threshold is defined as the percentile calculated for daily data recorded in a long period of time $[29,60]$. In our work, NCEP provides data every six hours, so that daily maximum air temperature and its corresponding RH are taken at 18 UTC to calculate the daily maximum HI from 1948 to 2015. Consequently, combining the heat wave NWS definition for regions with high $\mathrm{RH}$ in terms of HWs duration [22] and the definition for a very warm environment (Southern US) relative to a threshold [22] leads to the definition used in this work. Accordingly, here a heat wave is defined as at least three consecutive days with daily maximum $\mathrm{HI}$ greater than the 99.5 th percentile. A little higher threshold is considered here to account for Caribbean people's adaptation to warm and humid environments.

In order to compare the two climate periods (1948-1998 and 1999-2015), a unique threshold was used to identify heat waves. First, the threshold was calculated using the 99.5th percentile using daily maximum heat index from 1948 to 2015 and used for both climate periods. This threshold was calculated according to the common methodology found in the literature which takes a time period record of many years to calculate the percentile $[24,27,29,30]$. Posteriorly, a second threshold is computed from the first climate period (1948-1998) and used as a threshold for the second period (1999-2015) to determine the impact of the threshold calculation in the heat waves number frequency. Results show that there are no relevant changes in the heat waves number probability, particularly for events with high probabilities of occurrence. Consequently, the percentile calculated in the first climate period is selected in this work to account for heat waves development in the second climate period. On the other hand, GCMs dataset was obtained for two periods, 2026-2045 and 2081-2100. Daily heat index was calculated for both periods and the 99.5th percentile was estimated in the first 20 years to get the threshold. This threshold is also used to evaluate the heat waves numbers at the second period (2081-2100). This way, we can compare both periods to identify future changes in the heat wave number and intensity.

Statistical significance for temporal trends in time series is evaluated using the Mann-Kendall test. The parametric test is a commonly used method used to detect trends in climate data, but it requires independent and normally distributed data. Likewise, strong temporal autocorrelated data could generate artificial trends without statistical significance. An alternative is the nonparametric Mann-Kendall test which is a distribution-free test capable of handling weakly autocorrelated time series [61, 62]. A positive/negative test statistic $Z$ value represents increasing/decreasing trend in data. If the null hypothesis is not rejected, the variable's values in the time series will fluctuate around its average, instead of presenting a statistically significant linear trend. The rate of change or trend is estimated using the Theil-Sen approach $[61,63]$.

\section{Current IAR Climatology}

Intense HI could develop extreme HW events with a high impact on human health $[27,31,35,64,65]$ as well as in energy demand for air conditioning systems [66]. An early warning system is relevant to mitigate possible heat strokes' impact on the population's health. This warning system requires identifying possible synoptic atmospheric drivers of extreme heat waves events. In this manner, this section analyzes the $\mathrm{HI}$ climatology and these possible drivers.

The IAR climatology evolves from a low SST in the dry season with $25.7^{\circ} \mathrm{C}$ in average to more intense ocean surface warming in the ERS (seasonal average of $27.3^{\circ} \mathrm{C}$ ). In the LRS, the SST reaches its maximum value in the month of August with $28.3^{\circ} \mathrm{C}$ (Figure 2(a)). This seasonal ocean warming is translated into a warm pool spreading up to the Greater Antilles and even further. This seasonal warm pool enhances evaporation, increasing moisture content in the atmosphere with the largest values in the LRS. A second effect of a warmer ocean is the near-air surface temperature increase due to sensible heat flux exchange. The maximum air temperature peak is developed in the LRS, specifically in August $\left(27^{\circ} \mathrm{C}\right)$. In addition, the combination of the air temperature and $\mathrm{RH}$ allows calculating the $\mathrm{HI}$, which follows the SST and air temperature tendency, with a maximum peak of $29.7^{\circ} \mathrm{C}$ in August (Figure 2(a)). Consequently, current IAR ocean warming could lead to days with higher $\mathrm{HI}$ and likely a region with more intense HW events.

According to the IAR climatology, the LRS corresponds to the warmer season, where a high caution area for heat stroke spans further the Greater Antilles following the warm pool spread. The Greater and Lesser Antilles, Yucatan in Mexico, and the Southern American Caribbean coastline are areas with high caution because of $\mathrm{HI}$ ranges between 29 and $32^{\circ} \mathrm{C}$. The $\mathrm{HI}$ between 26 and $29^{\circ} \mathrm{C}$ denotes a low caution area for Central America and Mexico coastlines along with inland South America. In a similar way, Southern US depicts a low caution area with the exception of southern Florida where a heat stroke's high caution predominates (Figure 2(b)). In this season, the Bermuda-Azores high-pressure system is weakening (maximum intensity is observed in the ERS) and moving back to the Atlantic Ocean causing a SLP decrease in the IAR. This seasonal high-pressure system variation corresponds with the high caution area spread. According to the wind-evaporation-SST feedback process [15], during the LRS, the lower SLP in the region (with respect to the ERS) corresponds to a less intense wind speed and higher SST with a more stratified surface ocean [15], which impacts the HI's strength. Consequently, there is an inverse relationship between the HI and the SLP seasonal evolution. The high caution area boundary corresponds to a SLP between 1011 mbar along Mexico, Central America, and South America coastline and 1016 mbar further than the Greater Antilles (Figure 2(b)). On the other hand, the vertical pressure velocity averaged from 600 to 400 mbar points out an IAR dominated by an upward air motion with high SST and hence a more buoyant atmosphere. The Greater and Lesser Antilles depict an Omega vertical velocity between 


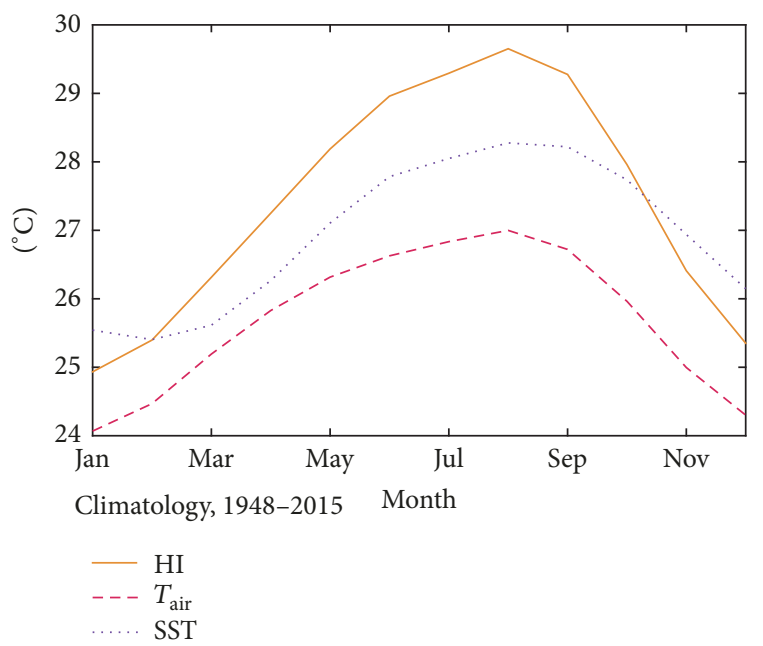

(a)

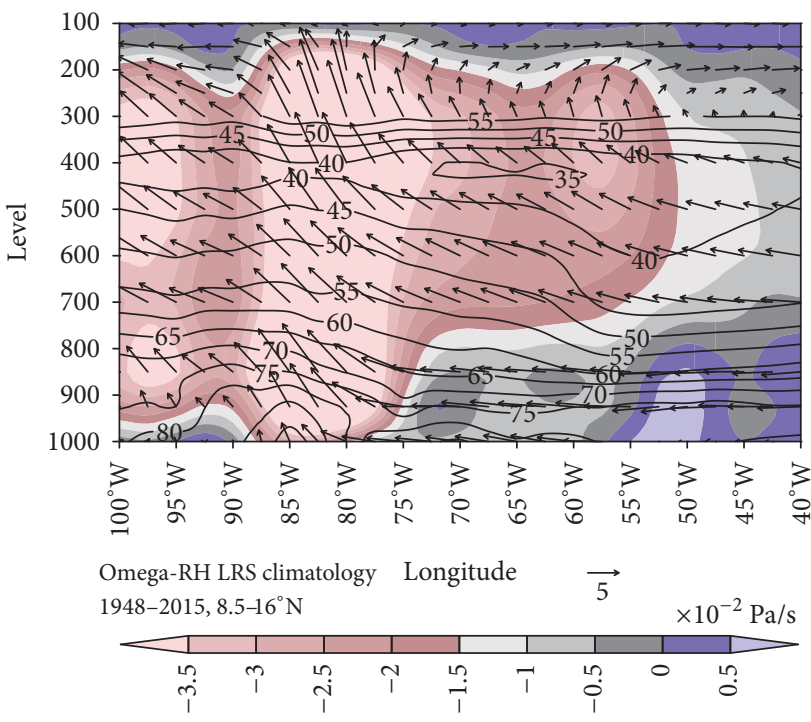

(c)

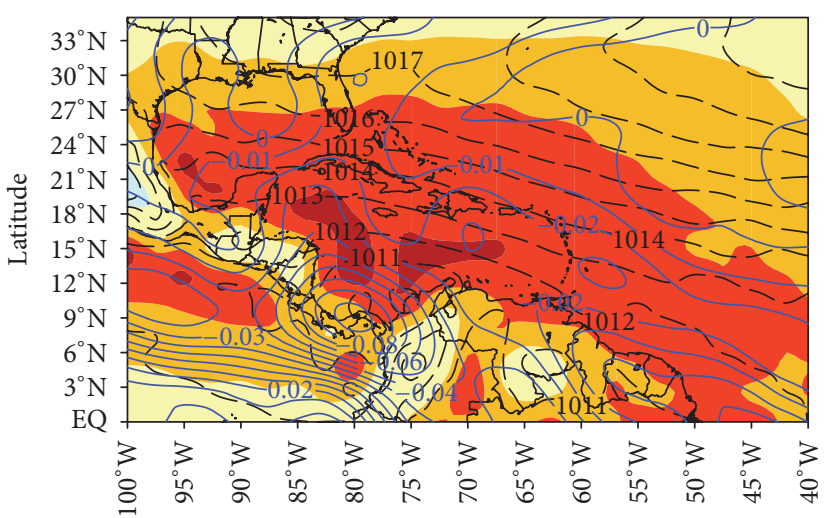

Heat index climatology Longitude $1948-2015$

$\left({ }^{\circ} \mathrm{C}\right)$ (b)

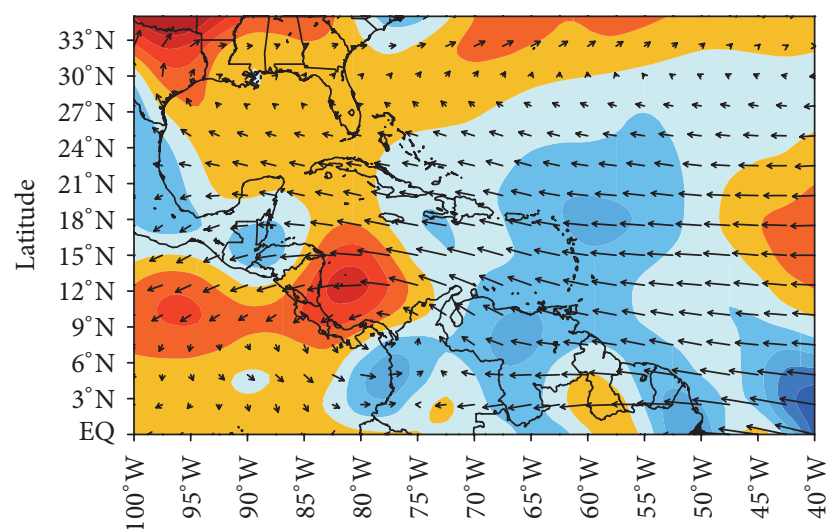

Warm advection climatology Longitude 850 mbar, 1948-2015

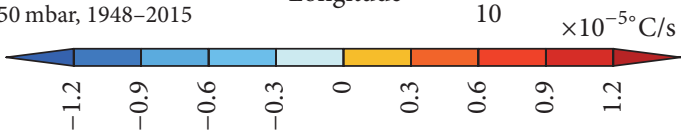

(d)

FIgURE 2: IAR climatology for (a) SST, air temperature, and HI. (b) Heat index in ${ }^{\circ} \mathrm{C}$ (color shades), SLP in mbar (dotted black contour line), vertical velocity in $\mathrm{Pa} / \mathrm{s}$ (blue contour line) in the LRS, (c) vertical velocity in color shades $\left(\times 10^{-2} \mathrm{~Pa} / \mathrm{s}\right.$ ), relative humidity in \% (black contour line), and wind vector in the LRS. (d) Warm/cold advection in color shades $\left(\times 10^{-5 \circ} \mathrm{C} / \mathrm{s}\right)$ and wind vector at $850 \mathrm{mbar}$ in the LRS.

-0.01 and $-0.02 \mathrm{~Pa} / \mathrm{s}$ while Central America and the Southern American Caribbean coastline are controlled by -0.02 and $-0.03 \mathrm{~Pa} / \mathrm{s}$ (Figure 2(b)). In a similar way, the wind velocity vertical cross section averaged in the meridional area 8.5 to $10^{\circ} \mathrm{N}$ denotes a region dominated by rising air in the LRS with RH between 50 and $40 \%$ in the atmosphere at the levels 600-400 mbar (Figure 2(c)). A regional circulation belt is developing from Central America to the western Main Developed Region (MDR), which enlarges in the LRS, generating a wider rising air area $\left(85^{\circ} \mathrm{W}-55^{\circ} \mathrm{W}\right)$. This atmospheric circulation corresponds with the high caution area's western border, where the sinking air is observed at the longitude $55^{\circ} \mathrm{W}$ (Figures 2(b) and 2(c)). The warm/cold advection at $850 \mathrm{mbar}$ is weakening season by season, with the weaker cold advection in the LRS and covering the Greater Antilles ( 0 to $\left.-0.3 \times 10^{-5 \circ} \mathrm{C} / \mathrm{s}\right)$, Mexico $\left(-0.3 \times 10^{-5}\right.$ to $\left.-0.6 \times 10^{-5 \circ} \mathrm{C} / \mathrm{s}\right)$, and Northern South America $\left(-0.3 \times 10^{-5}\right.$ to $\left.-0.6 \times 10^{-5 \circ} \mathrm{C} / \mathrm{s}\right)$. In this season and in the Caribbean region, cold advection does not convey true cold air because the temperature gradients are very small, and hence it does not reduce drastically the surface air temperature. According to Figure 2(d), a warm advection is noticed on Central America $\left(0.3 \times 10^{-5}\right.$ to $\left.1.2 \times 10^{-5 \circ} \mathrm{C} / \mathrm{s}\right)$, Gulf of Mexico (0 to $0.3 \times$ $10^{-5 \circ} \mathrm{C} / \mathrm{s}$ ), and Southern US and Northern Cuba (0 to 0.3 $\times 10^{-5 \circ} \mathrm{C} / \mathrm{s}$ ). Consequently, warm-weaker cold advection in combination with lower SLP and higher SST leads to HI intensification and turns the IAR in a high caution area for heat stroke/exhaustion. 


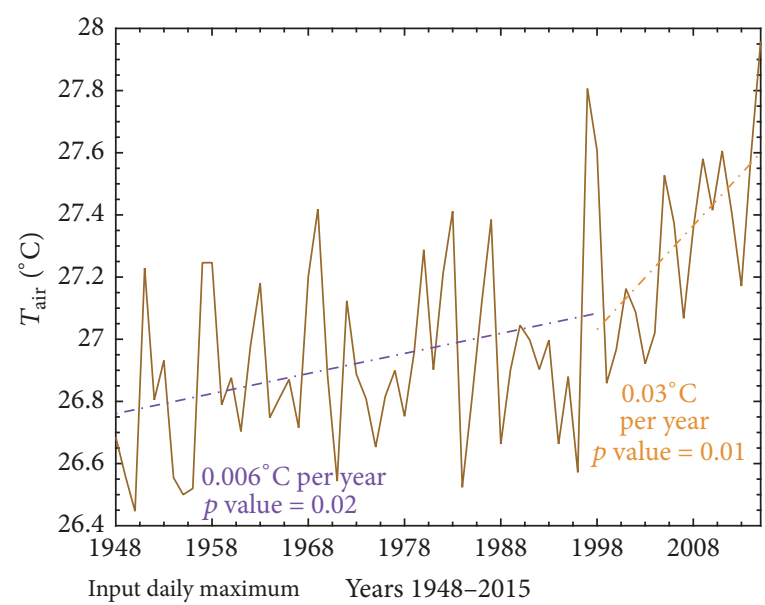

- Annual max. $T_{\text {air }}:$ IAR

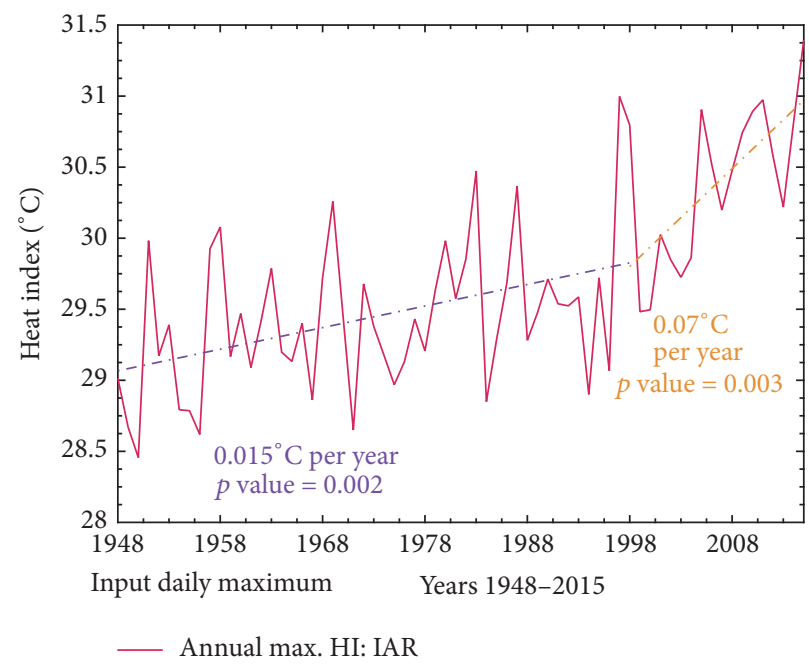

(b)

FIGURE 3: Climate disruption acceleration since 1998 on the IAR using (a) the maximum annual temperature and (b) the maximum annual heat index.

\section{Climate Disruption}

Near-surface air temperatures at synoptic scale are related to the SST in the IAR following the seasonal warm pool spread. In addition, evaporation intensification following the wind-evaporation-SST feedback modifies the moisture content in the atmosphere as well as the RH. The HI is calculated using the air temperature and the relative humidity and hence is affected by changes in the SST. Accordingly, the air temperature and HI could be suitable indicators of regional climate disruption. The annual maximum air temperature obtained from the monthly average of daily maximum air temperature shows an air temperature rate of increase of $0.006^{\circ} \mathrm{C}$ per year (1948-1998) with good statistical significance $(p$ value $=0.02)$. Since 1998, an accelerated air temperature increase has been observed with an annual trend of $0.03^{\circ} \mathrm{C}$ (Figure $\left.3(\mathrm{a})\right)$ and proper statistical significance $(p$ value $=0.01)$. In a similar way, the annual maximum $\mathrm{HI}$ possesses a tendency to increase from 1948 to 1998 with a rate of $0.015^{\circ} \mathrm{C}$ per year, but since 1998 , the $\mathrm{HI}$ has been rising in an accelerated manner $\left(0.07^{\circ} \mathrm{C}\right.$ per year $)$ with suitable statistical significance (Figure 3(b)). Therefore, the year 1998 is selected as the baseline to compare two climate periods and to identify the regional climate disruption effects on the HWs frequency.

The climate difference between 1999-2015 and 1948-1998 depicts atmospheric warming in all IAR seasons. The lowest change is observed in the DS with $\mathrm{HI}$ disruption of $0.16^{\circ} \mathrm{C}$ and a maximum change of $0.74^{\circ} \mathrm{C}$ in the LRS. The SLP change follows an inverse relationship with the HI showing a positive change in the DS ( 0.3 mbar) and negative difference in the LRS $(-0.17$ mbar) where the SLP is decreasing and the HI obtains its maximum peak (Figure 4(a)). In this last rainy season, a positive $\mathrm{HI}$ change spans across the whole IAR with the highest disruption in the Southern Greater Antilles including Puerto Rico and the western MDR $\left(1.5-2.0^{\circ} \mathrm{C}\right)$. The second more relevant change is observed in the Northern Greater Antilles (Cuba and Dominican Republic), Gulf of Mexico, Florida, and the South American Caribbean coastline $\left(0.9-1.5^{\circ} \mathrm{C}\right)$, while the lowest disruption is detected in Mexico, Central America, and South America inland $\left(0.3-0.6^{\circ} \mathrm{C}\right)$. In contrast, a small area covering part of Guyana and Suriname in Southern America has a HI decrease between 0 and $-0.3^{\circ} \mathrm{C}$ (Figure $4(\mathrm{~b})$ ). This regional warming and tendency to intensify the heat index in the region happens at the same time with the SLP decrease. The higher SLP difference ranges from -0.3 to -0.5 mbar overlapping with the highest HI change area, while the lowest negative or even zero SLP change corresponds to the lowest HI climate difference encompassing Mexico, Central America, and South America (Figure 4(b)). According to the SLP anomaly time series in the IAR (1948-2015), in the LRS, the maximum anomaly is 0.9 mbar while the lowest one is represented by -0.86 mbar. In addition, the average negative SLP anomaly holds a low value $(-0.16$ mbar $)$. Consequently, the SLP climate difference between the two selected climate periods represents a significant regional climate disturbance. In a similar way, the vertical air motion change impacts the regional atmospheric warming. In the LRS, positive Omega velocity averaged from $600 \mathrm{mbar}$ to $400 \mathrm{mbar}$ dominates the Caribbean region and the MDR (0.01-0.02 Pa/s) showing a tendency to enhance sinking dry air and to warm up the surface (Figure 4(b)). Furthermore, the Omega velocity vertical cross section points out a sinking air dry intensification from the upper atmosphere $(\Delta \mathrm{RH}=-14 \%$ at $300 \mathrm{mbar})$ to the surface (Figure $4(\mathrm{c})$ ). Warm advection is strengthening across the Greater Antilles $\left(0.2 \times 10^{-5 \circ} \mathrm{C} / \mathrm{s}\right)$, Lesser Antilles $\left(0.3 \times 10^{-5}-0.5 \times 10^{-5 \circ} \mathrm{C} / \mathrm{s}\right)$, Mexico, and Southern US with $0.2 \times 10^{-5 \circ} \mathrm{C} / \mathrm{s}$ (see Figure $4(\mathrm{~d})$ ). Weaker cold advection with respect to the ERS brings less cold air to the region, which comes together with positive HI change. Consequently, a SLP decrease, sinking dry air intensification, and warm and cold advection weakening converge to intensify the HI in the IAR. 


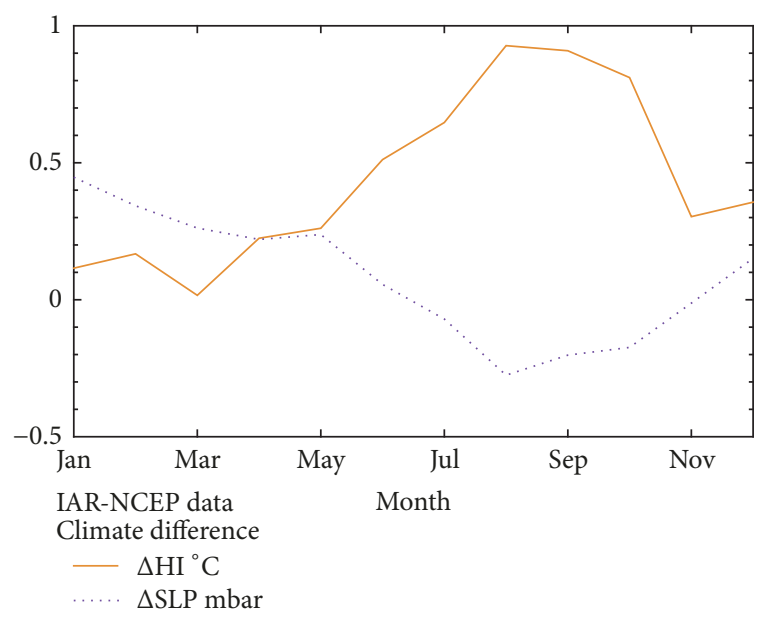

(a)

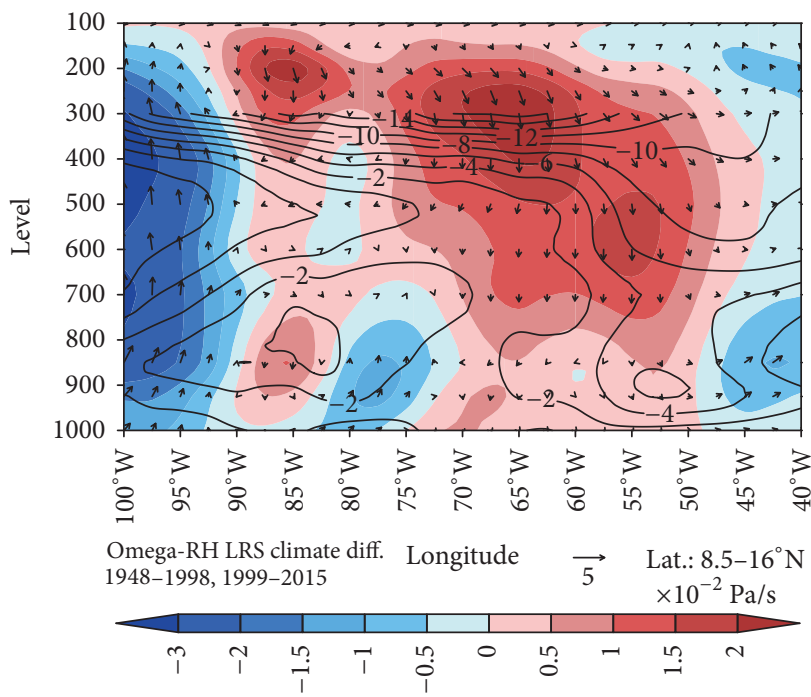

(c)

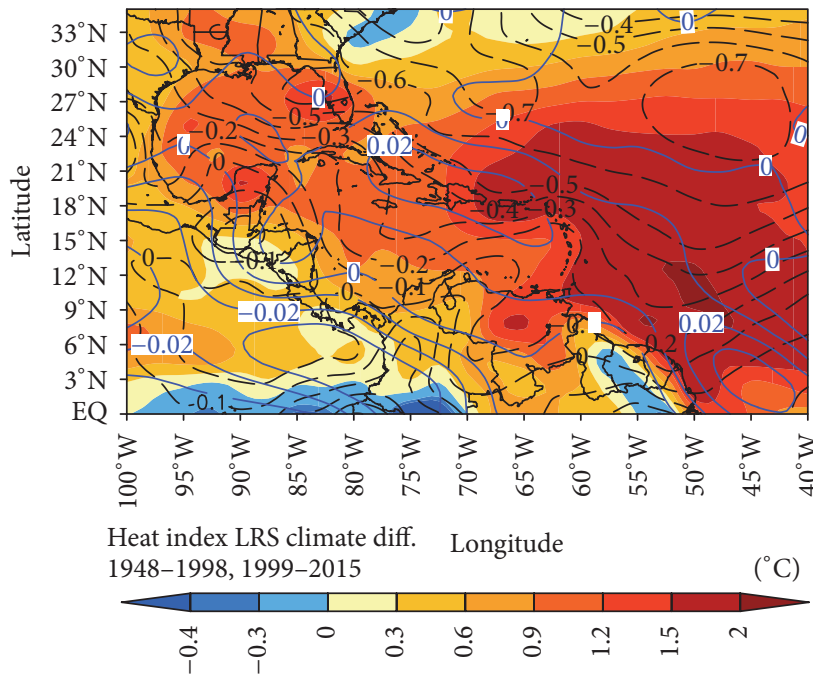

(b)

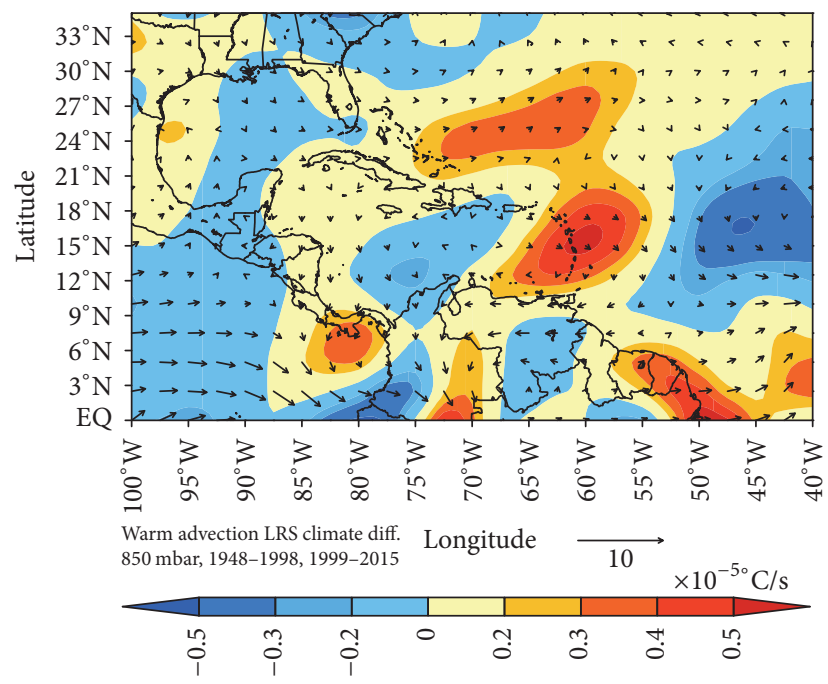

(d)

Figure 4: (a) Climate difference between 1999-2015 and 1948-1998 for HI and SLP. (b) LRS heat index change in ${ }^{\circ} \mathrm{C}$ (color shades), SLP change (dotted black contour line), and vertical velocity change in $\mathrm{Pa} / \mathrm{s}$ (blue contour line). (c) LRS vertical velocity change in color shades $\left(\times 10^{-2} \mathrm{~Pa} / \mathrm{s}\right)$, relative humidity in $\%$ (black contour line), and wind vector. (d) LRS warm $/ \mathrm{cold}$ advection change in color shades $\left(\times 10^{-5 \circ} \mathrm{C} / \mathrm{s}\right)$ and wind vector at 850 mbar.

\section{Current Climate Heat Waves}

Annual HWs events were calculated in every grid point across the IAR to later accumulate them. This approach allows identifying the total HWs number time evolution during the past 68 years. Low HWs number is observed in the first 51 years with 28 events on average over the IAR. Since 1999, HWs number has increased in an accelerated manner with an average value of 84 events (Figure 5(a)). This HWs number growth is related to the HI strengthening due to the conjunction of SLP decrease, warm-weaker cold advection, and sinking air intensification.

HWs number time series is disaggregated to observe hot day events distribution across the IAR. Low HWs number is concentrated in Southern Central America and Caribbean coast of South America (2-6 events) during the first climate period (1948-1998), while a higher number of events were identified in Mexico (10-14 events) and Northern Central America (10-16 events) as shown in Figure 5(b). Furthermore, the Caribbean is characterized as a region without heat waves events. On the other hand, the second climate period (1999-2015) is compared against the first climate to detect possible HWs disruption. The highest HWs number change is focalized in the Greater and Lesser Antilles with an increase between 8 and 14 events. The second most impacted area covers Guyana, Suriname, and French Guiana in South America (2-10 events' increase). In contrast, Central America and Mexico represent a region with HWs activity decrease, with a HWs number reduction between -12 and zero events (see Figure 5(c)). 

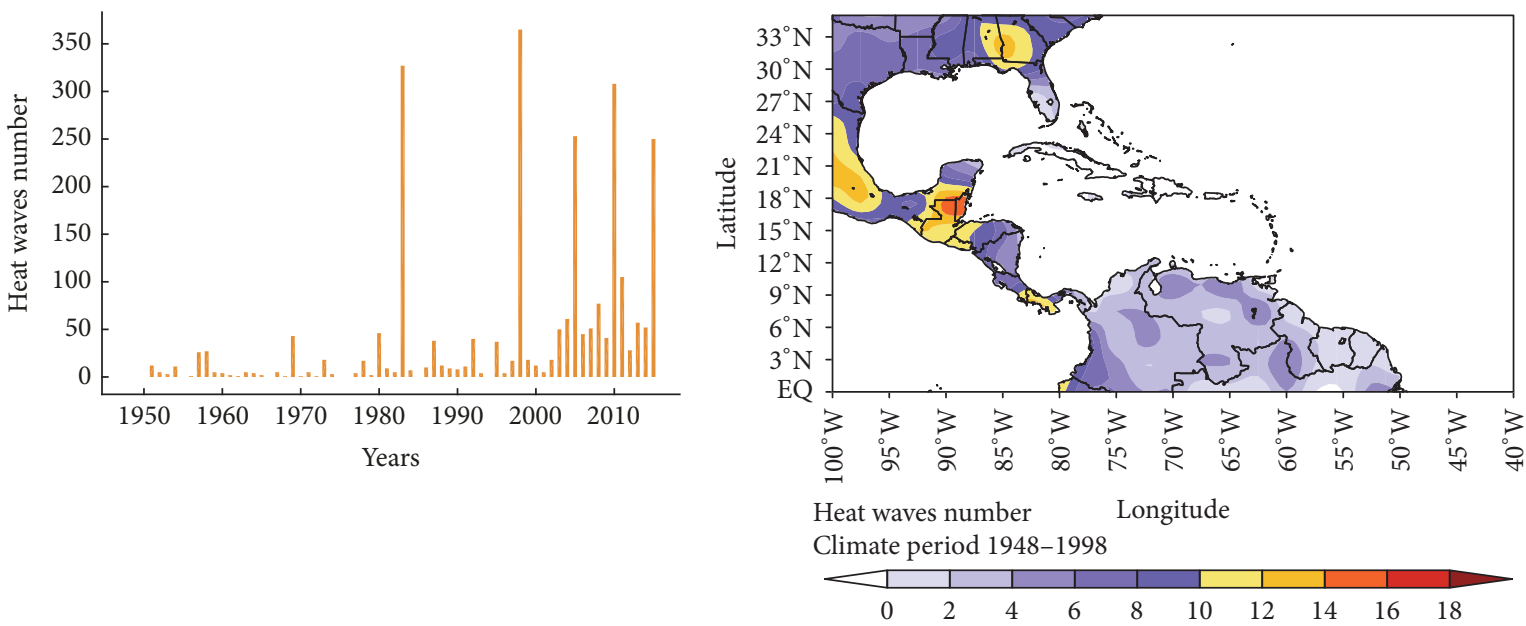

(a)

(b)

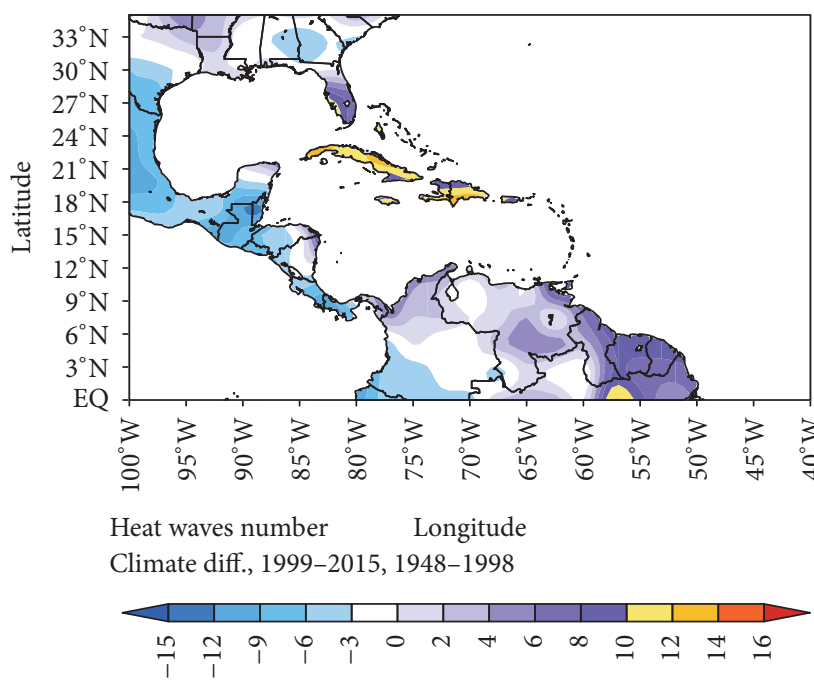

(c)

FIGURE 5: (a) Annual HWs number accumulated across the IAR for the period 1948-2015. (b) Heat waves number in the LRS in the first climate period 1948-1998. (c) Heat waves number change in the LRS between the climate periods 1999-2015 and 1948-1998.

Heat waves number frequency was calculated in the two climate periods to detect any change in the region. The relative frequency from 1948 to 1998 points out a probability of 0.43 to develop three or fewer HWs events per month in the whole IAR. Larger HWs numbers have a lower probability to develop so that an interval between 6 and 15 events holds an occurrence probability of 0.19 . In addition, greater events than 15 and less than 102 represent a low accumulated probability $(0.13)$. In the second climate period, there is a shift in the HWs occurrence probability (relative frequency distribution). In contrast with the first period, three or fewer HWs events' development per month holds a probability of 0.22 , while a larger number of HWs events increase its probability. HWs events between 6 and 15 represent a probability of 0.33 , which translates to almost twice the probability of the first climate period (Figure 6(a)). Furthermore, HWs events between 15 and 102 have a higher probability which is more than twice the probability in the preceding period.
During a HW event, the HI evolves day by day until reaching the highest value. This maximum $\mathrm{HI}$ defines the maximum HW amplitude. In the first climate period, the maximum HI during a HW event converges between 34 and $36^{\circ} \mathrm{C}$ with a probability of 0.29 . Events with hotter days have lower occurrence probability, such as HI ranging between 36 and $38^{\circ} \mathrm{C}$ with a probability of 0.16 . Additionally, the statistical parameters, skewness and kurtosis, define a maximum amplitude distribution left skewed with low symmetry (skewness $=-0.26$ ) and with a close shape to Gaussian distribution (kurtosis $=-0.02$ ). In the next 17 years, there is a clear shift in the maximum HW amplitude with a maximum $\mathrm{HI}$ peak between 36 and $38^{\circ} \mathrm{C}$ and an occurrence probability of 0.42 (Figure 6(b)). Furthermore, a distribution shape change is detected. A more intense left skewed tail is characterized in this second climate period (skewness $=-0.58)$, while a sharper peak (kurtosis $=1.28$ ) depicts a deviation from the Gaussian distribution observed in the first 


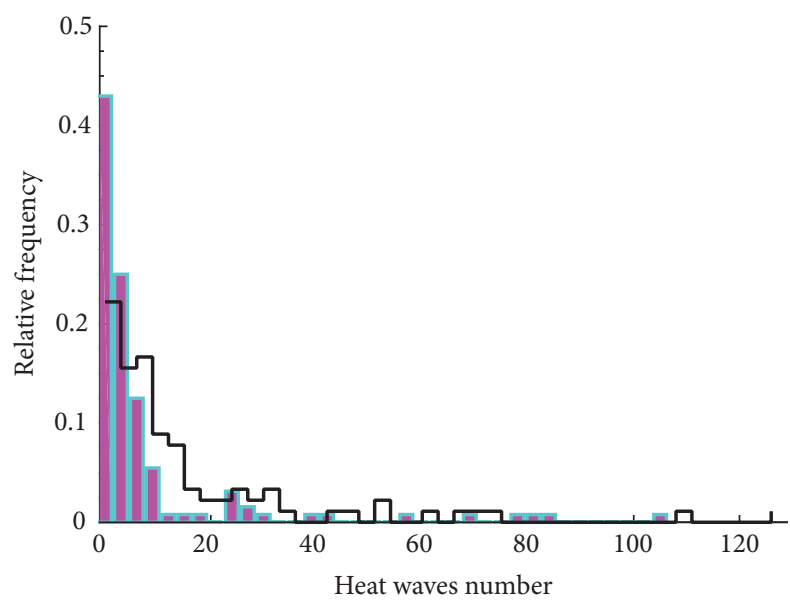

[1948-1998

- 1999-2015

(a)

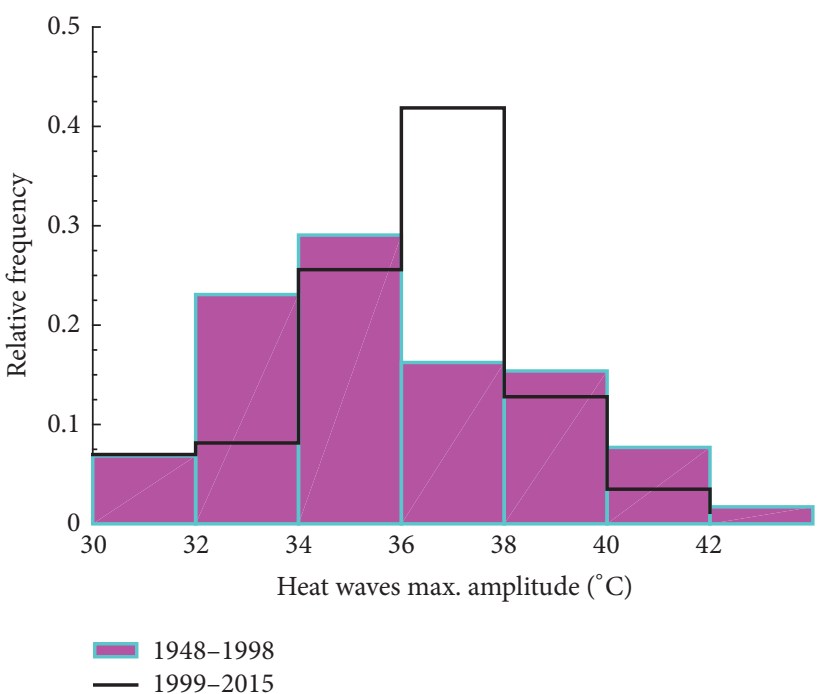

(b)

FIGURE 6: (a) Heat waves frequency of the whole region. (b) Regional average of heat waves maximum amplitude.

climate period (Figure 6(b)). Therefore, the IAR warming expressed by changes in the SST, air temperature, and HI is causing HWs events intensification in both events number and amplitude.

\section{Heat Waves Projection Using General Circulation Models}

Heat index computed from GCMs was validated recently by the authors using NCEP reanalysis data. Low errors were obtained, ranging from $1.0 \%$ to $5 \%$ [66]. Heat index trend analysis was performed using a multimodel ensemble mean. Two scenarios, RCP4.5 and RCP8.5, were selected to represent the regional warming likelihood along the 21st century. Positive HI trend at a rate of $0.041^{\circ} \mathrm{C}$ per year was projected in the RCP4.5 scenario during the period 2026-2045. Using the Mann-Kendall test, this trend has suitable statistical significance with $p$ value close to zero. In contrast, in the last two decades (2081-2100), HI did not show a trend but rather a variability around the mean $\mathrm{HI}$ value of $29.1^{\circ} \mathrm{C}$ (Figure $7(\mathrm{a})$ ). A fast $\mathrm{HI}$ increase is pointed out in the RCP8.5 scenario and in the first future climate period 2026-2045 with a rate of increase of $0.06^{\circ} \mathrm{C}$ per year. In the second future climate period (2081-2100), accelerated $\mathrm{HI}$ intensification is projected at a rate of $0.12^{\circ} \mathrm{C}$ per year (Figure $7(\mathrm{~b})$ ). In this scenario, trends have proper statistical significance with $p$ values close to zero.

On the other hand, HI climatology calculated from 2081 to 2100 was compared against the first future climate. The climate difference between these two future climate periods depicts a maximum HI change of $2^{\circ} \mathrm{C}$ in August (RCP4.5), while the scenario RCP8.5 stands for higher HI change with an increment of $6.4^{\circ} \mathrm{C}$ (Figure $7(\mathrm{c})$ ). This RCP8.5 scenario projects the largest climate change in every season due to greater greenhouse gas release and concentration in the atmosphere, causing a warmer atmosphere and the likelihood to develop stronger extreme events such as HWs.

Positive HI change in both scenarios RCP4.5 and RCP8.5 translates into HWs events increase and intensification. In the first scenario RCP4.5, the future climate period 2026-2045 denotes a small monthly average HWs number (14 events), while the annual average events are 124 . In the same scenario, the time series of the average heat waves number remarks an evident increase in the second future climate period (2081-2100) with 158 events per month and 1848 events per year on average across the whole IAR (Figure 8(a) and Table 1). This HWs time evolution corresponding to the scenario RCP4.5 is disaggregated into a spatial distribution to show regions with $\mathrm{HWs}$ number difference between the two future climate periods. Low HWs events were projected in the Caribbean region (2-8 events) during the first future climate. Greater Antilles show HWs activities between 2 and 5 events, while Central America and Northern South America hold some spots without HWs. Substantial HWs activities are simulated in the second future climate, particularly in the Caribbean region with the second highest events increase with respect to the first future climate. The Greater Antilles, including Cuba, Dominican Republic, and Puerto Rico, point out HWs number increase between 80 and 100 events. Central America, Honduras, and Guatemala depict a positive difference in the number of events between 40 and 60, while the third highest HW events increases are concentrated in Nicaragua, Costa Rica, and Panama (60-100 events). Northern South America follows the same tendency as the southern Central America with Central Colombia ranging between 30 and 80 events' increase, with its Caribbean coastline pointing out the highest events (around 100-120 more events than the first future climate period). Furthermore, Venezuela denotes 60-100 events' increase in the last two decades of the 21st century (Figure $8(\mathrm{~b}))$. 


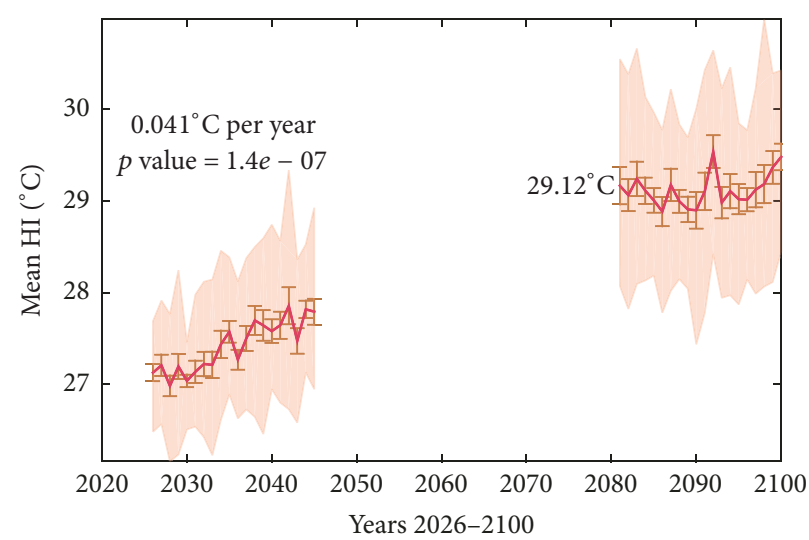

- IAR

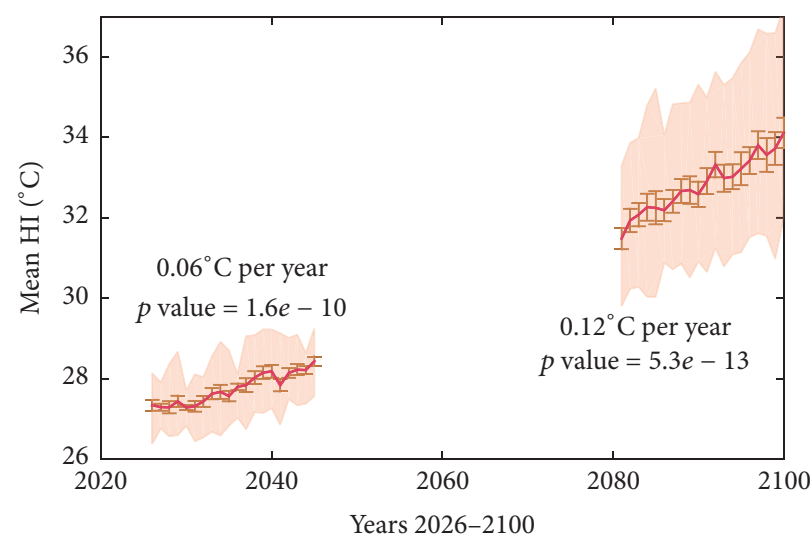

IAR

(b)

(a)

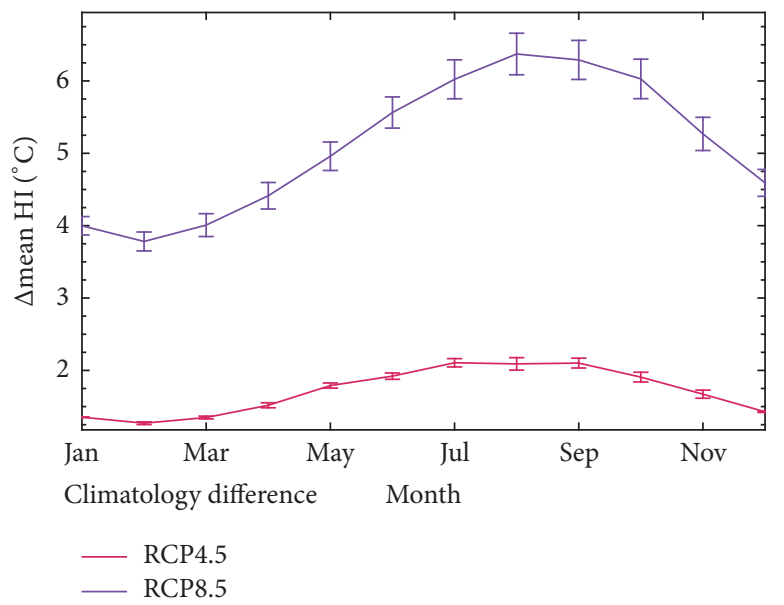

(c)

FIGURE 7: Multimodel ensemble mean for (a) annual mean HI time series, RCP4.5 scenario. (b) Annual mean HI time series, RCP8.5 scenario. (c) HI climate difference for RCP4.5 and RCP8.5.

Following with the analysis in the first scenario RCP4.5, the heat waves number distribution indicates an occurrence probability of 0.39 to develop 1 to 10 heat waves and 0.23 for 10 and 20 events in the period 2026-2045. In the last 20 years of the 21st century, the probability distribution changed noticeably with a higher probability to develop a large amount of heat waves, with 0.35 for 10 and 80 events and 0.26 for events between 100 and 200 (Figure 8(c)). On the other hand, HWs maximum amplitude probability distribution shows high asymmetry in the first climate period with a left skewed tail (skewness of -1.4) and a sharper peak, heavily tailed (kurtosis equal to 2.7). Hence, this probability distribution does not follow a Gaussian distribution, where hot day events mostly tend to have maximum $\mathrm{HI}$ between 30 and $36^{\circ} \mathrm{C}$ with a probability of 0.41 . There is no shift in the distribution shape of the maximum HWs duration during the period 2081-2100, with skewness and kurtosis of -1.14 and 1.1, respectively. Furthermore, the probability to develop maximum heat index between 30 and $36^{\circ} \mathrm{C}$ increased to 0.48 (Figure $8(\mathrm{~d})$ ).

The second scenario, the RCP8.5, represents a more active IAR in terms of HWs development. The HWs number increased remarkably in this scenario when the hot day events are identified using the same threshold as for the scenario RCP4.5. The monthly average HWs number in RCP8.5 corresponds to 34 events in the first future climate while the annual average increased by almost three times (356 events) the RCP4.5 scenario. The second future climate denotes a relevant intensification with a monthly average of 372 events and an annual average increase by two and a half times with respect to the scenario RCP4.5 (Figure 9(a) and Table 1). The HWs change corresponding to the scenario RCP8.5 is shown as a spatial distribution to identify regions with high/low hot day events. In the period 2026-2045, most of the HWs are developing in the Caribbean region, with larger events in the Greater Antilles (21-30 events), including the Dominican Republic (12-18 events) and Puerto Rico (12-15 events). In the second future climate period, massive heat waves activities are projected across the whole region, particularly in Central America and Mexico with 110 to 180 events' increase in the last two decades of the 21st century with respect to the first future climate. In addition, the Northern 

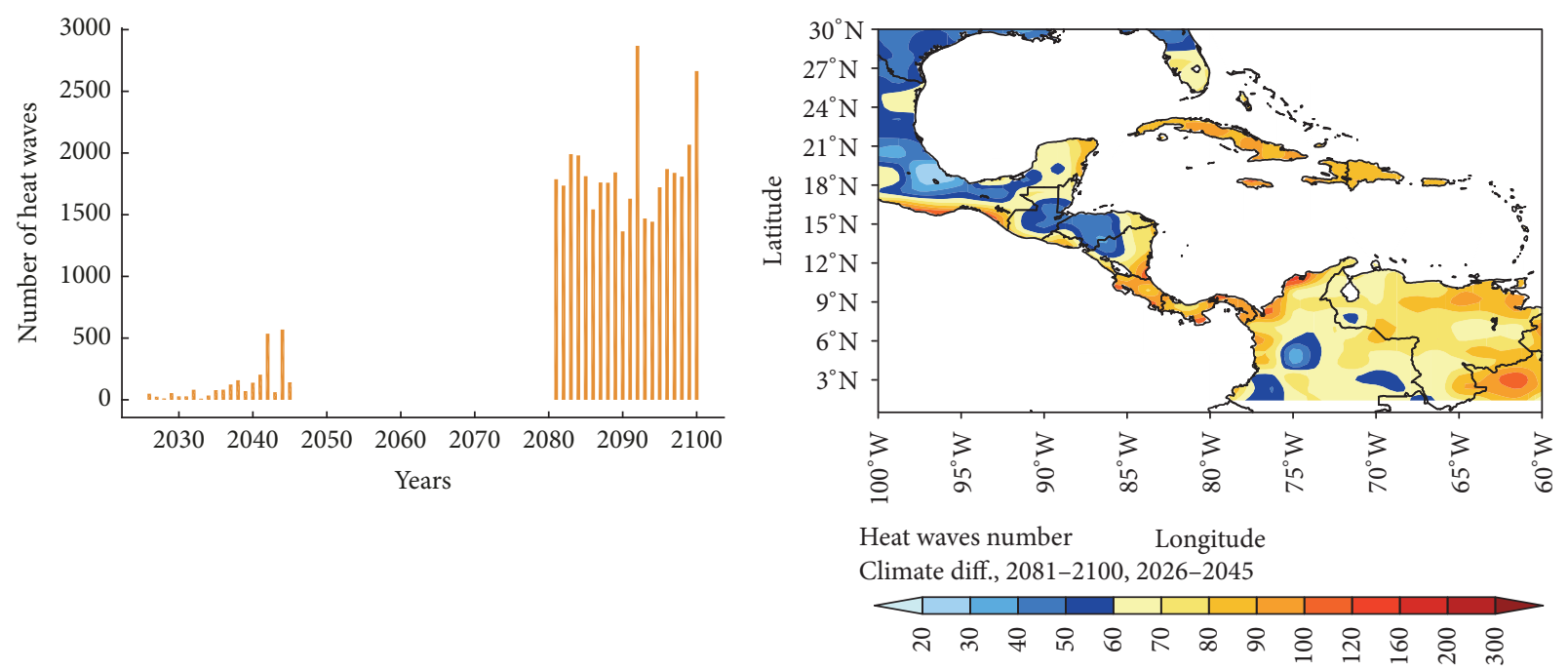

(a)

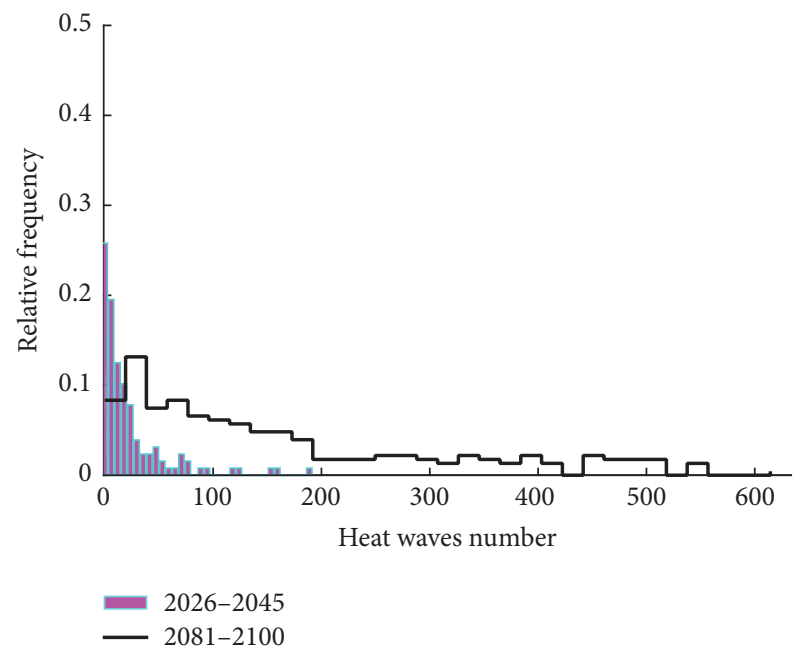

(c)

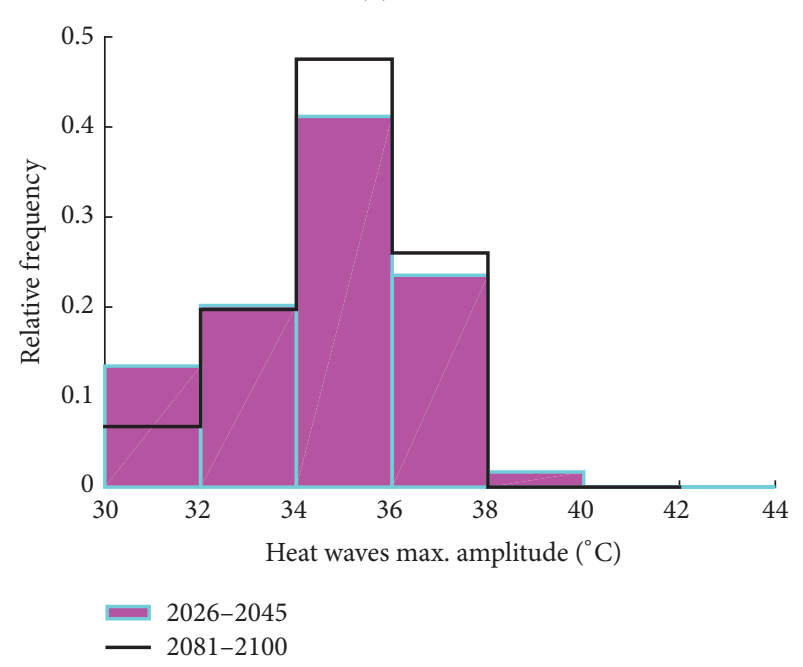

(d)

FIGURE 8: Multimodel ensemble mean for the RCP4.5 scenario: (a) annual time series, (b) HWs number change between the climate periods 2081-2100 and 2026-2045, (c) HWs frequency of the whole IAR including the ocean area, and (d) regional average of HWs maximum amplitude.

South America denotes even higher events with an increase between 140 and 360 events (Figure 9(b)). In this scenario, the Caribbean represents an area with lower heat stroke activities, with Cuba projecting HWs rise between 80 and 100 events and the Dominican Republic between 80 and 140 events, and Puerto Rico depicts future events intensification ranging from 80 to 100 events.

On the other hand, according to the scenario RCP8.5, there is a substantial change in HWs number probability distribution when both climate periods are compared. In the second period (2081-2100), a higher probability to develop HWs events between 204 and 420 is observed with a probability of 0.54 (Figure 9(c)). Additionally, the HWs maximum amplitude has a probability of 0.49 to develop events with maximum $\mathrm{HI}$ between 34 and $36^{\circ} \mathrm{C}$ during the first future climate. A left skewed distribution (skewness of -0.91) and sharper peak (kurtosis of 1.44) are a characteristic of this period. In the last two decades of the 21st century, HWs maximum amplitude distribution changes to a Gaussian distribution with skewness and kurtosis of -0.0472 and -0.4989 , respectively. Furthermore, there is a clear shift in the maximum HI during HWs events. The maximum amplitude is concentrated now between 36 and $38^{\circ} \mathrm{C}$ with a probability of 0.41 (Figure $9(\mathrm{~d})$ ).

These heat waves' increase could cause heat-related illness intensification with more frequent heat exhaustion and even heat stroke $[34,35,64,65,67,68]$. A high population mortality could be recurrent in the future, primarily in elderly populations and people with preexisting medical conditions and without air conditioning systems. In addition, to mitigate the harmful impact on health [31,32], more energy will be required to cool down room environments. 
TABLE 1: Total annual heat waves number for the whole IAR.

\begin{tabular}{|c|c|c|c|c|c|}
\hline \multirow{2}{*}{ Years } & \multicolumn{5}{|c|}{ Heat waves number, IAR } \\
\hline & RCP4.5 & RCP8.5 & Years & RCP4.5 & RCP8.5 \\
\hline 2026 & 50 & 63 & 2081 & 1787 & 4540 \\
\hline 2027 & 25 & 136 & 2082 & 1736 & 4599 \\
\hline 2028 & 11 & 89 & 2083 & 1991 & 4724 \\
\hline 2029 & 54 & 195 & 2084 & 1981 & 4551 \\
\hline 2030 & 28 & 132 & 2085 & 1812 & 4635 \\
\hline 2031 & 28 & 42 & 2086 & 1543 & 4316 \\
\hline 2032 & 81 & 27 & 2087 & 1761 & 4508 \\
\hline 2033 & 9 & 109 & 2088 & 1759 & 4567 \\
\hline 2034 & 35 & 154 & 2089 & 1843 & 4535 \\
\hline 2035 & 78 & 89 & 2090 & 1365 & 4514 \\
\hline 2036 & 82 & 549 & 2091 & 1630 & 4413 \\
\hline 2037 & 124 & 262 & 2092 & 2869 & 4442 \\
\hline 2038 & 158 & 374 & 2093 & 1469 & 4381 \\
\hline 2039 & 71 & 849 & 2094 & 1443 & 4612 \\
\hline 2040 & 138 & 541 & 2095 & 1722 & 4539 \\
\hline 2041 & 204 & 257 & 2096 & 1870 & 4210 \\
\hline 2042 & 536 & 487 & 2097 & 1839 & 4353 \\
\hline 2043 & 62 & 561 & 2098 & 1809 & 4468 \\
\hline 2044 & 569 & 846 & 2099 & 2067 & 3950 \\
\hline 2045 & 142 & 1348 & 2100 & 2664 & 4402 \\
\hline Annual avg. & 124 & 356 & Annual avg. & 1848 & 4463 \\
\hline Monthly avg. & 14 & 34 & Monthly avg. & 158 & 372 \\
\hline
\end{tabular}

\section{Discussion and Conclusions}

This article explores current $\mathrm{HI}$ trends and HWs change due to regional warming, as well as future projection in the intraAmericas region under the RCP4.5 and RCP8.5 scenarios.

The IAR climatology denotes a SST increase season by season causing an air temperature peak in the month of August which translates together with the $\mathrm{RH}$ into maximum human discomfort expressed by high HI peak in this month. The warmest season is characterized by a high caution area for heat stress encompassing the Caribbean region as well as Yucatan in Mexico and the Caribbean coast of South America. This large area is in agreement with the warm pool season expansion, the regional circulation belt stretching deep in the western MDR, and the SLP decrease following the wind-evaporation-SST feedback process.

A significant climate disruption was identified in the year 1998, with an accelerated air temperature and HI increase since this year with a positive rate of $0.03^{\circ} \mathrm{C}$ and $0.07^{\circ} \mathrm{C}$ per year, respectively. Two climate periods were selected to identify changes in $\mathrm{HI}$ and feasible variables driving this regional atmospheric warming. The climate difference between 1999-2015 and 1948-1998 pointed out HI intensification of $0.74^{\circ} \mathrm{C}$ in the LRS as an average across the IAR. A clear inverse relationship between $\mathrm{HI}$ and SLP change was detected. Furthermore, sinking dry air intensification together with warm advection strengthening and weaker cold advection tendency can increase the regional atmospheric warming.
The accelerated HI rise conducts changes in HWs activities across the IAR during the LRS. In the second climate period, HWs activities intensification was detected, mainly due to negative SLP change, sinking dry air enhancement, and warm-weaker cold advection with respect to the ERS. Furthermore, there is a clear change in HWs number frequency in the last 17 years (1999-2015), as well as in the HWs maximum amplitude distribution.

The multimodel ensemble mean for future $\mathrm{HI}$ and HWs shows a future IAR warmer atmosphere, projecting a large amount of HWs, particularly in the last two decades of the 21st century, where higher HI values are simulated. In the scenario RCP4.5, substantial HWs activities are predicted, mainly in the Caribbean region. From 2081 to 2100, HWs number probability distribution changed noticeably, while the maximum amplitude distribution did not show a distribution shape variation. Despite this, there is a probability increase to develop a maximum $\mathrm{HI}$ between 30 and $36^{\circ} \mathrm{C}$. In the business-as-usual scenario (RCP8.5), massive HWs events are projected across the whole region, particularly in Central America, Mexico, and Northern South America. Additionally, there is a variation in both HWs number and maximum amplitude distribution shape with the maximum $\mathrm{HI}$ shifted to the interval $36-38^{\circ} \mathrm{C}$. The socioeconomic implications of these projections for the region may be significant in terms of human health and energy demand projections, as the authors recently reported [66]. 

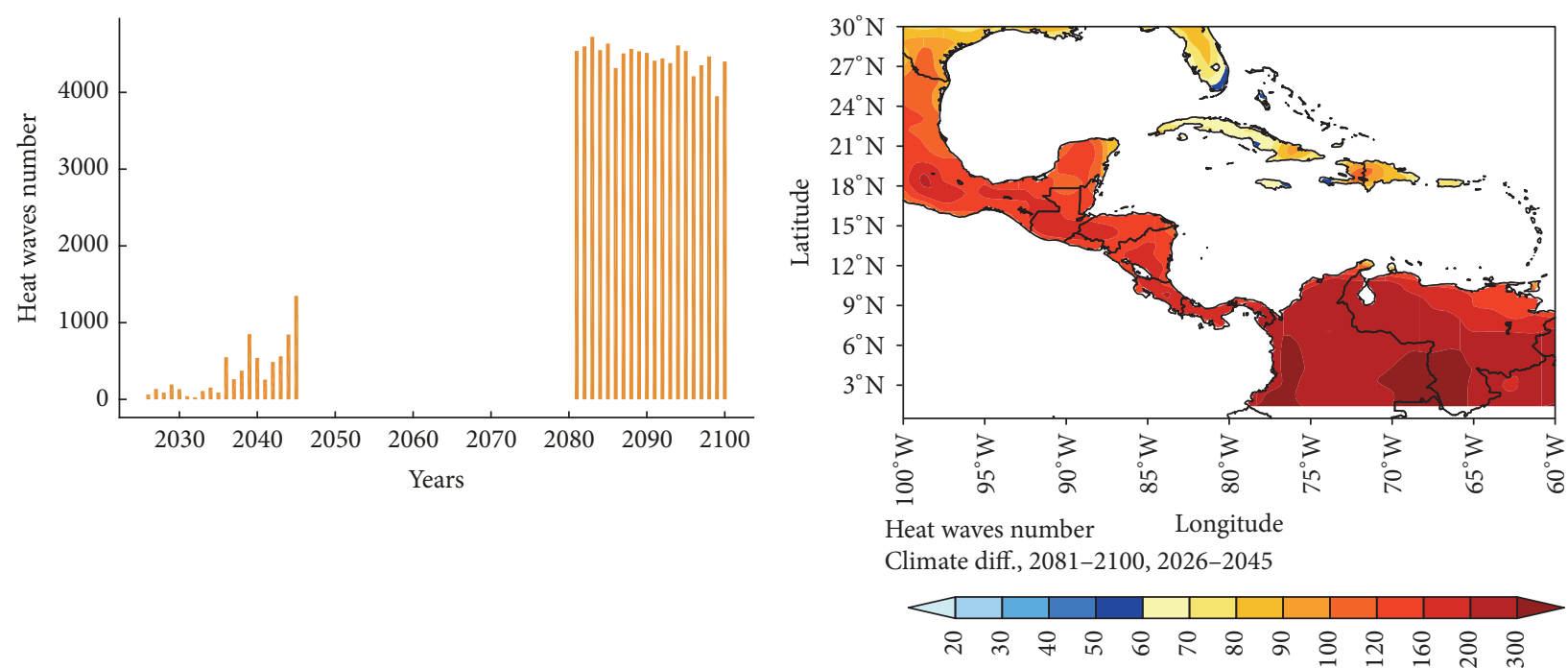

(a)

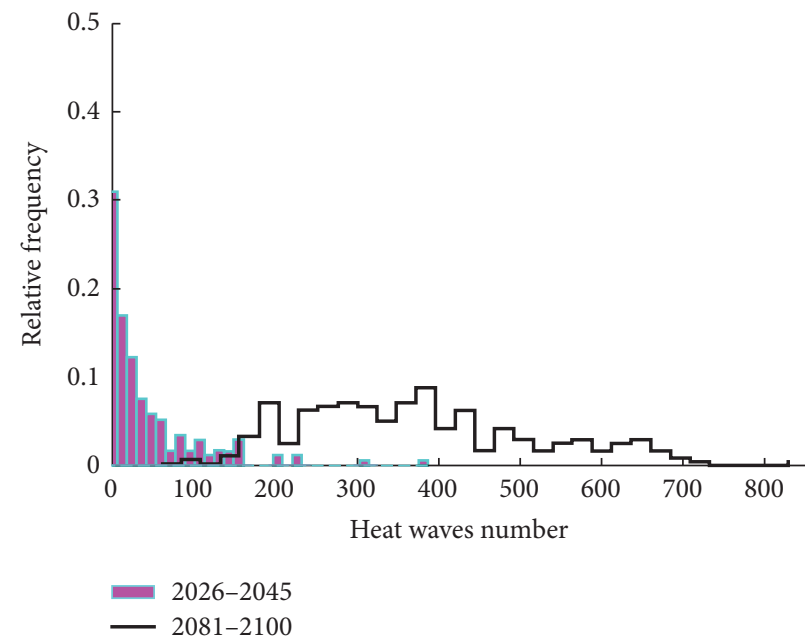

(b)

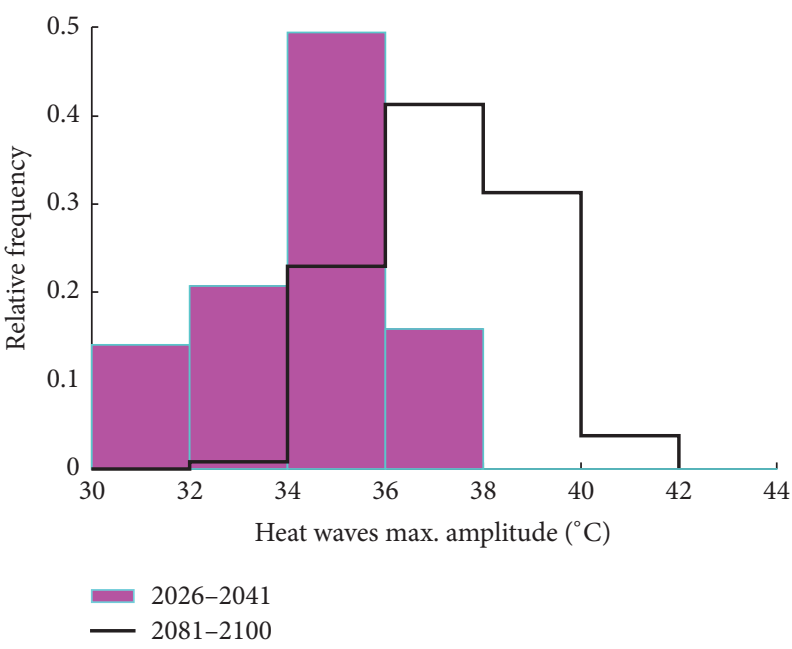

(c)

(d)

Figure 9: Multimodel ensemble mean for the RCP8.5 scenario: (a) annual time series, (b) HWs number change between the climate periods 2081-2100 and 2026-2045, (c) HWs frequency of the whole region including the ocean area, and (d) regional average of HWs maximum amplitude.

\section{Conflicts of Interest}

The authors declare that there are no conflicts of interest regarding the publication of this article.

\section{Acknowledgments}

The analysis process was conducted at the high performance computing facilities at City College of New York. This work was sponsored by the National Oceanic and Atmospheric Administration (NOAA), Office of Education Partnership Program Award NA11SEC4810004, and by the United States Agency for International Development (USAID) under Cooperative Agreement no. AID-517A15-00002 and the US National Foundation Grant no. CBET-1438324.

\section{References}

[1] J. A. Amador, "The Intra-Americas Sea low-level jet: Overview and future research," Annals of the New York Academy of Sciences, vol. 1146, pp. 153-188, 2008.

[2] S. Curtis, "Daily precipitation distributions over the intraAmericas sea and their interannual variability," Atmósfera, vol. 26, no. 2, pp. 243-259, 2013.

[3] A. M. Mestas-Nuñez, D. B. Enfield, and C. Zhang, "Water vapor fluxes over the Intra-Americas Sea: Seasonal and interannual variability and associations with rainfall," Journal of Climate, vol. 20, no. 9, pp. 1910-1922, 2007.

[4] D. W. Gamble and S. Curtis, "Caribbean precipitation: review, model and prospect," Progress in Physical Geography, vol. 32, no. 3, pp. 265-276, 2008.

[5] M. E. Angeles, J. E. González, N. D. Ramírez-Beltrán, C. A. Tepley, and D. E. Comarazamy, "Origins of the Caribean 
rainfall bimodal behavior," Journal of Geophysical Research: Atmospheres, vol. 115, Article ID D11106, 2010.

[6] E. Glenn, D. Comarazamy, J. E. González, and T. Smith, "Detection of recent regional sea surface temperature warming in the Caribbean and surrounding region," Geophysical Research Letters, vol. 42, no. 16, pp. 6785-6792, 2015.

[7] N. Hosannah, J. Gonzalez, R. Rodriguez-Solis et al., "The convection, aerosol, and synoptic-effects in the tropics (cast) experiment," BAMS, pp. 1593-1600, 2017.

[8] I. Folkins and C. Braun, "Tropical rainfall and boundary layer moist entropy," Journal of Climate, vol. 16, no. 11, pp. 1807-1820, 2003.

[9] M. Taylor, D. Enfield, and A. Chen, "Influence of the tropical atlantic versus the tropical pacific on caribbean rainfall," Journal of Geophysical Research: Atmosphere, vol. 107, no. C9, pp. 10-14, 2002.

[10] M. E. Angeles, J. E. Gonzalez, D. J. Erickson III, and J. L. Hernández, "Predictions of future climate change in the caribbean region using global general circulation models," International Journal of Climatology, vol. 27, no. 5, pp. 555-569, 2007.

[11] J. Moran, Online Weather Studies, American Meteorological Association, Boston, Mass, USA, 2002.

[12] C. Wang, "Variability of the Caribbean Low-Level Jet and its relations to climate," Climate Dynamics, vol. 29, no. 4, pp. 411422, 2007.

[13] A. Giannini, Y. Kushnir, and M. A. Cane, "Interannual variability of Caribbean rainfall, ENSO, and the Atlantic Ocean," Journal of Climate, vol. 13, no. 2, pp. 297-311, 2000.

[14] B. E. Mapes, P. Liu, and N. Buenning, "Indian monsoon onset and the Americas midsummer drought: Out-of-equilibrium responses to smooth seasonal forcing," Journal of Climate, vol. 18, no. 7, pp. 1109-1115, 2005.

[15] B. Qu, A. Gabric, J. Zhu, D. Lin, F. Qian, and M. Zhao, "Correlation between sea surface temperature and wind speed in greenland sea and their relationships with nao variability," Water Science and Engineering Journal, vol. 5, no. 3, pp. 304-315, 2012.

[16] V. Magaña and E. Caetano, "Temporal evolution of summer convective activity over the Americas warm pools," Geophysical Research Letters, vol. 32, no. 2, pp. 1-4, 2005.

[17] F. Chouza, O. Reitebuch, A. Benedetti, and B. Weinzierl, "Saharan dust long-range transport across the Atlantic studied by an airborne Doppler wind lidar and the MACC model," Atmospheric Chemistry and Physics, vol. 16, no. 18, pp. 1158111600, 2016.

[18] A. A. Chen and M. A. Taylor, "Investigating the link between early season Caribbean rainfall and the El Niño+1 year," International Journal of Climatology, vol. 22, no. 1, pp. 87-106, 2002.

[19] M. A. Taylor, T. S. Stephenson, A. Owino, A. A. Chen, and J. D. Campbell, "Tropical gradient influences on Caribbean rainfall," Journal of Geophysical Research: Atmospheres, vol. 116, no. 18, Article ID D00Q08, 2011.

[20] M. E. Angeles, J. E. González, D. J. Erickson III, and J. L. Hernández, "The impacts of climate changes on the renewable energy resources in the Caribbean region," Journal of Solar Energy Engineering, vol. 132, no. 3, pp. 0310091-03100913, 2010.

[21] V. Moron, R. Frelat, P. K. Jean-Jeune, and C. Gaucherel, "Interannual and intra-annual variability of rainfall in Haiti (1905-2005)," Climate Dynamics, vol. 45, no. 3-4, pp. 915-932, 2015.
[22] N. Ramirez, J. Gonzalez, J. Castro, M. Angeles, E. Harmsen, and C. Salazar, "Analysis of the heat index in the mesoamerica and caribbean region," Journal of Applied Climatology and Meteorology, vol. 56, pp. 2905-2925, 2017.

[23] M. Beniston, D. B. Stephenson, O. B. Christensen et al., "Future extreme events in European climate: an exploration of regional climate model projections," Climatic Change, vol. 81, no. 1, pp. 71-95, 2007.

[24] G. A. Meehl and C. Tebaldi, "More intense, more frequent, and longer lasting heat waves in the 21st century," Science, vol. 305, no. 5686, pp. 994-997, 2004.

[25] M. Zampieri, S. Russo, S. di Sabatino, M. Michetti, E. Scoccimarro, and S. Gualdi, "Global assessment of heat wave magnitudes from 1901 to 2010 and implications for the river discharge of the Alps," Science of the Total Environment, vol. 571, pp. 1330-1339, 2016.

[26] S. Russo, A. Dosio, R. G. Graversen et al., "Magnitude of extreme heat waves in present climate and their projection in a warming world," Journal of Geophysical Research: Atmospheres, vol. 119, no. 22, pp. 12500-12512, 2014.

[27] G. Brooke Anderson and M. L. Bell, "Heat waves in the United States: Mortality risk during heat waves and effect modification by heat wave characteristics in 43 U.S. communities," Environmental Health Perspectives, vol. 119, no. 2, pp. 210-218, 2011.

[28] T. T. Smith, B. F. Zaitchik, and J. M. Gohlke, "Heat waves in the United States: Definitions, patterns and trends," Climatic Change, vol. 118, no. 3-4, pp. 811-825, 2013.

[29] P. J. Robinson, "On the definition of a heat wave," Journal of Applied Meteorology and Climatology, vol. 40, no. 4, pp. 762775, 2001.

[30] K. Hayhoe, S. Sheridan, L. Kalkstein, and S. Greene, "Climate change, heat waves, and mortality projections for Chicago," Journal of Great Lakes Research, vol. 36, no. 2, pp. 65-73, 2010.

[31] G. Luber and M. McGeehin, "Climate change and extreme heat events," American Journal of Preventive Medicine, vol. 35, no. 5, pp. 429-435, 2008.

[32] J. A. Patz, D. Campbell-Lendrum, T. Holloway, and J. A. Foley, "Impact of regional climate change on human health," Nature, vol. 438, no. 7066, pp. 310-317, 2005.

[33] A. J. McMichael, R. E. Woodruff, and S. Hales, "Climate change and human health: present and future risks," The Lancet, vol. 367, no. 9513, pp. 859-869, 2006.

[34] P. Méndez-Lázaro, O. Martínez-Sánchez, R. Méndez-Tejeda, E. Rodríguez, and N. Schmitt-Cortijo, "Extreme heat events in san juan puerto rico: trends and variability of unusual hot weather and its possible effects on ecology and society," Journal of Climatology and Weather Forecasting, vol. 3, no. 2, pp. 1-7, 2015.

[35] P. A. Méndez-Lázaro, C. M. Pérez-Cardona, E. Rodríguez et al., "Climate change, heat, and mortality in the tropical urban area of San Juan, Puerto Rico," International Journal of Biometerology, pp. 1-9, 2016.

[36] P. Méndez-Lázaro, F. E. Muller-Karger, D. Otis, M. J. McCarthy, and E. Rodríguez, "A heat vulnerability index to improve urban public health management in San Juan, Puerto Rico," International Journal of Biometerology, pp. 1-14, 2017.

[37] J. Gonzalez, M. Georgescu, M. Lemos, N. Hosannah, and D. Niyogi, "Climate change's pulse in central america and the Caribbean," EoS, vol. 98, 2017.

[38] IPCC, Climate Change 2001: The Scientific Basis. Contribution of Working Group I to the Third Assessment Report of the Intergovernmental Panel on Climate Change, Cambridge University 
Press, Cambridge, United Kingdom and New York, NY, USA, 2001.

[39] N.-C. Lau and M. J. Nath, "A model study of heat waves over North America: Meteorological aspects and projections for the twenty-first century," Journal of Climate, vol. 25, no. 14, pp. 47614764, 2012.

[40] A. Amengual, V. Homar, R. Romero et al., "Projections of heat waves with high impact on human health in Europe," Global and Planetary Change, vol. 119, pp. 71-84, 2014.

[41] D. Birgmark, El Niño-Southern Oscillation and North Atlantic Oscillation Induced Sea Surface Temperature Variability in the Caribbean Sea, University of Gothenburg, Department of Earth Sciences, 2014.

[42] A. Giannini, M. A. Cane, and Y. Kushnir, "Interdecadal changes in the ENSO Teleconnection to the Caribbean Region and the North Atlantic Oscillation," Journal of Climate, vol. 14, no. 13, pp. 2867-2879, 2001.

[43] A. Giannini, J. C. H. Chiang, M. A. Cane, Y. Kushnir, and R. Seager, "The ENSO teleconnection to the Tropical Atlantic Ocean: Contributions of the remote and local SSTs to rainfall variability in the Tropical Americas," Journal of Climate, vol. 14, no. 24, pp. 4530-4544, 2001.

[44] V. Magaña, J. A. Amador, and S. Medina, "The midsummer drought over Mexico and Central America," Journal of Climate, vol. 12, no. 6, pp. 1577-1588, 1999.

[45] IPCC, Climate Change 2013: The Physical Science Basis. Contribution of Working Group I to the Fifth Assessment Report of the Intergovernmental Panel on Climate Change, Cambridge University Press, Cambridge, United Kingdom and New York, NY, USA, 2013.

[46] IPCC, pecial Report on Emissions Scenarios. A Special Report of Working Group III of the Intergovernmental Panel on Climate Change, Cambridge University Press, Cambridge, United Kingdom and New York, NY, USA, 2000.

[47] R. Moss, M. Babiker, S. Brinkman et al., “Towards New Scenarios for Analysis of Emissions, Climate Change, Impacts, and Response Strategies," Technical Summary, Intergovernmental Panel on Climate Change, Geneva, Switzerland, 2008.

[48] K. E. Taylor, R. J. Stouffer, and G. A. Meehl, "An overview of CMIP5 and the experiment design," Bulletin of the American Meteorological Society, vol. 93, no. 4, pp. 485-498, 2012.

[49] G. A. Meehl, L. Goddard, J. Murphy et al., "Decadal prediction: can it be skillful?" Bulletin of the American Meteorological Society, vol. 90, no. 10, pp. 1467-1485, 2009.

[50] J. Holmboe, G. Forsythe, and W. Gustin, Dynamic Meteorology, John Wiley and Sons Inc., New York, NY, USA, 1945.

[51] J. Wallace and P. Hobbs, Atmospheric Science An Introductory Survey, Academic Press, New York, NY, USA, 2006.

[52] M. Jacobson, Fundamentals of Atmospheric Modeling, Cambridge University Press, Cambridge, UK, 2005.

[53] R. G. Steadman, "The assessment of sultriness. Part I. A temperature-humidity index based on human physiology and clothing science.", Journal of Applied Meteorology and Climatology, vol. 18, no. 7, pp. 861-873, 1979.

[54] R. Stull, Meteorology for Scientists and Engineers, Brooks/Cole, Belmont, Calif, USA, 2000.

[55] NWS, The Heat Index Equation, Natl. Weather Serv. Weather Predict. Cent, http://www.wpc.ncep.noaa.gov/html/ heatindex_equation.shtml.

[56] G. Brooke Anderson, M. L. Bell, and R. D. Peng, "Methods to calculate the heat index as an exposure metric in environmental health research," Environmental Health Perspectives, vol. 121, no. 10, pp. 1111-1119, 2013.

[57] A. L. Hass, K. N. Ellis, L. R. Mason, J. M. Hathaway, and D. A. Howe, "Heat and humidity in the city: Neighborhood heat index variability in a mid-sized city in the Southeastern United States," International Journal of Environmental Research and Public Health, vol. 13, no. 1, article no. 117, 2016.

[58] S. Russo, J. Sillman, and A. Sterl, "Humid Heat Waves at Diferent Warming Levels," Science, vol. 7, pp. 1-7, 2017.

[59] M. Mohan, A. Gupta, and S. Bhati, "A modified approach to analyze thermal comfort classification," Atmospheric and Climate Sciences, vol. 4, no. 1, pp. 7-19, 2014.

[60] M. Nitschke, G. R. Tucker, A. L. Hansen, S. Williams, Y. Zhang, and P. Bi, "Impact of two recent extreme heat episodes on morbidity and mortality in Adelaide, South Australia: A caseseries analysis," Environmental Health: A Global Access Science Source, vol. 10, no. 1, article no. 42, 2011.

[61] A. M. Carmona and G. Poveda, "Detection of long-term trends in monthly hydro-climatic series of Colombia through Empirical Mode Decomposition," Climatic Change, vol. 123, no. 2, pp. 301-313, 2014.

[62] K. H. Hamed, "Trend detection in hydrologic data: the MannKendall trend test under the scaling hypothesis," Journal of Hydrology, vol. 349, no. 3-4, pp. 350-363, 2008.

[63] Q. Zhang, V. P. Singh, P. Sun, X. Chen, Z. Zhang, and J. $\mathrm{Li}$, "Precipitation and streamflow changes in China: Changing patterns, causes and implications," Journal of Hydrology, vol. 410, no. 3-4, pp. 204-216, 2011.

[64] E. Scoccimarro, P. Giuseppe, and S. Gualdi, "The Role of Humidity in Determining Scenarios of Perceived Temperature Extremes in Europe," Environmental Research Letters, vol. 12, no. 11, pp. 1-8, 2017.

[65] C. C. Macpherson and M. Akpinar-Elci, "Caribbean heat threatens health, well-being and the future of humanity," Public Health Ethics, vol. 8, no. 2, pp. 196-208, 2015.

[66] M. Angeles, J. Gonzalez, and N. Ramirez, "Impacts of climate change on building energy demands in the Intra-Americas Region," Journal of Theoretical and Applied Climatology, pp. 114, 2017.

[67] G. Xie, Y. Guo, S. Tong, and L. Ma, "Calculate excess mortality during heatwaves using Hilbert-Huang transform algorithm," BMC Medical Research Methodology, vol. 14, no. 1, article no. 35, 2014.

[68] K. Zhang, T.-H. Chen, and C. E. Begley, "Impact of the 2011 heat wave on mortality and emergency department visits in Houston, Texas," Environmental health : a global access science source, vol. 14, p. 11, 2015. 

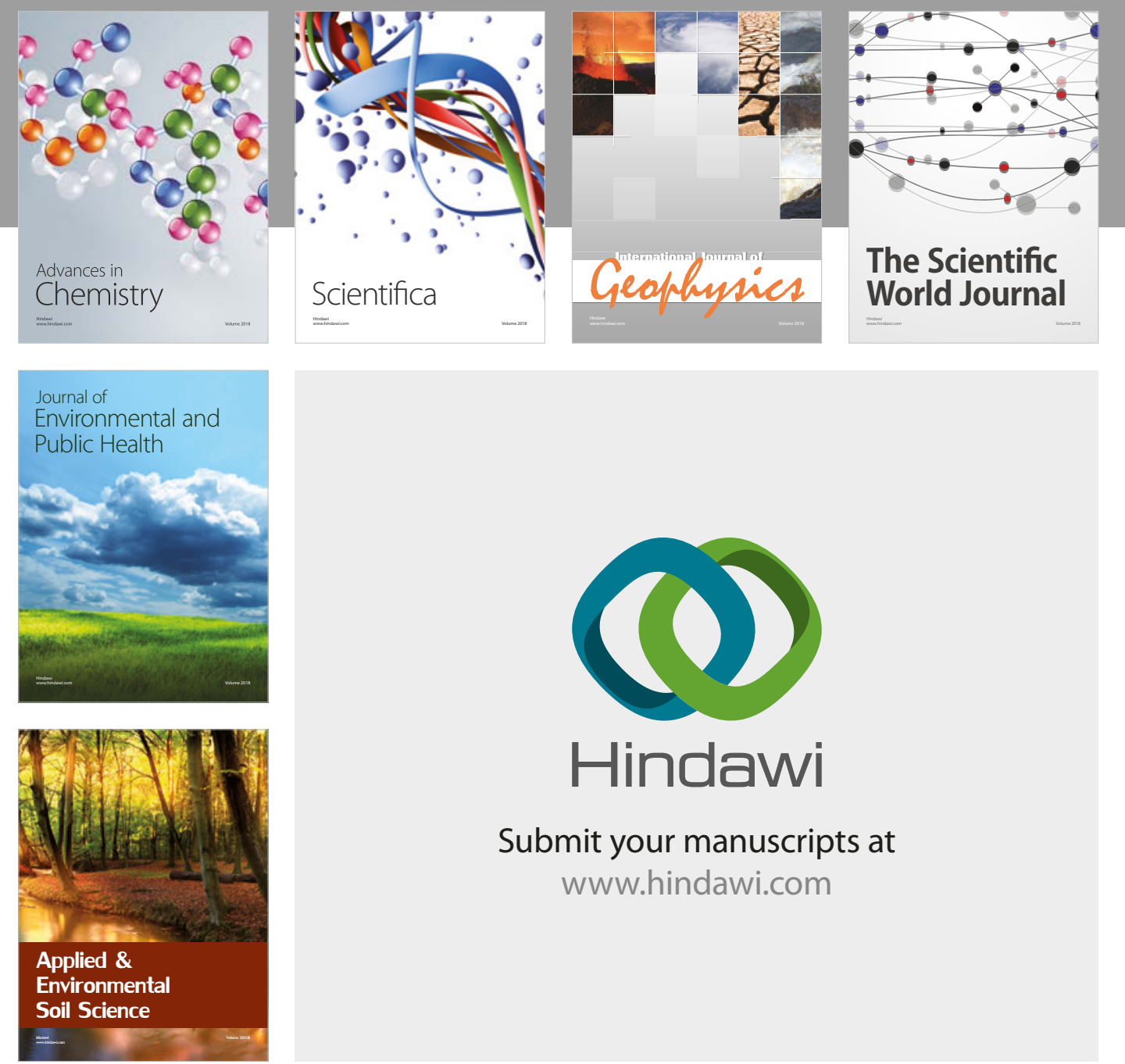

The Scientific

\section{World Journal}
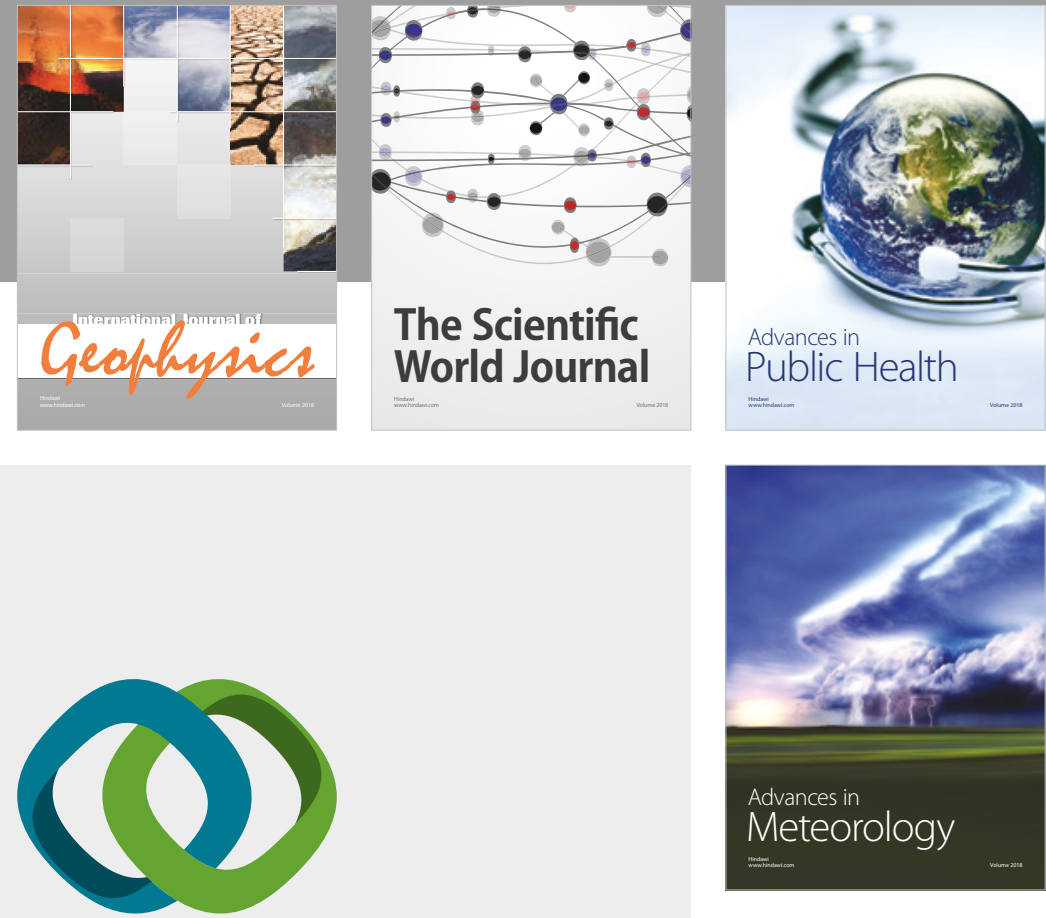

Advan

Public Health

\section{Hindawi}

Submit your manuscripts at

www.hindawi.com
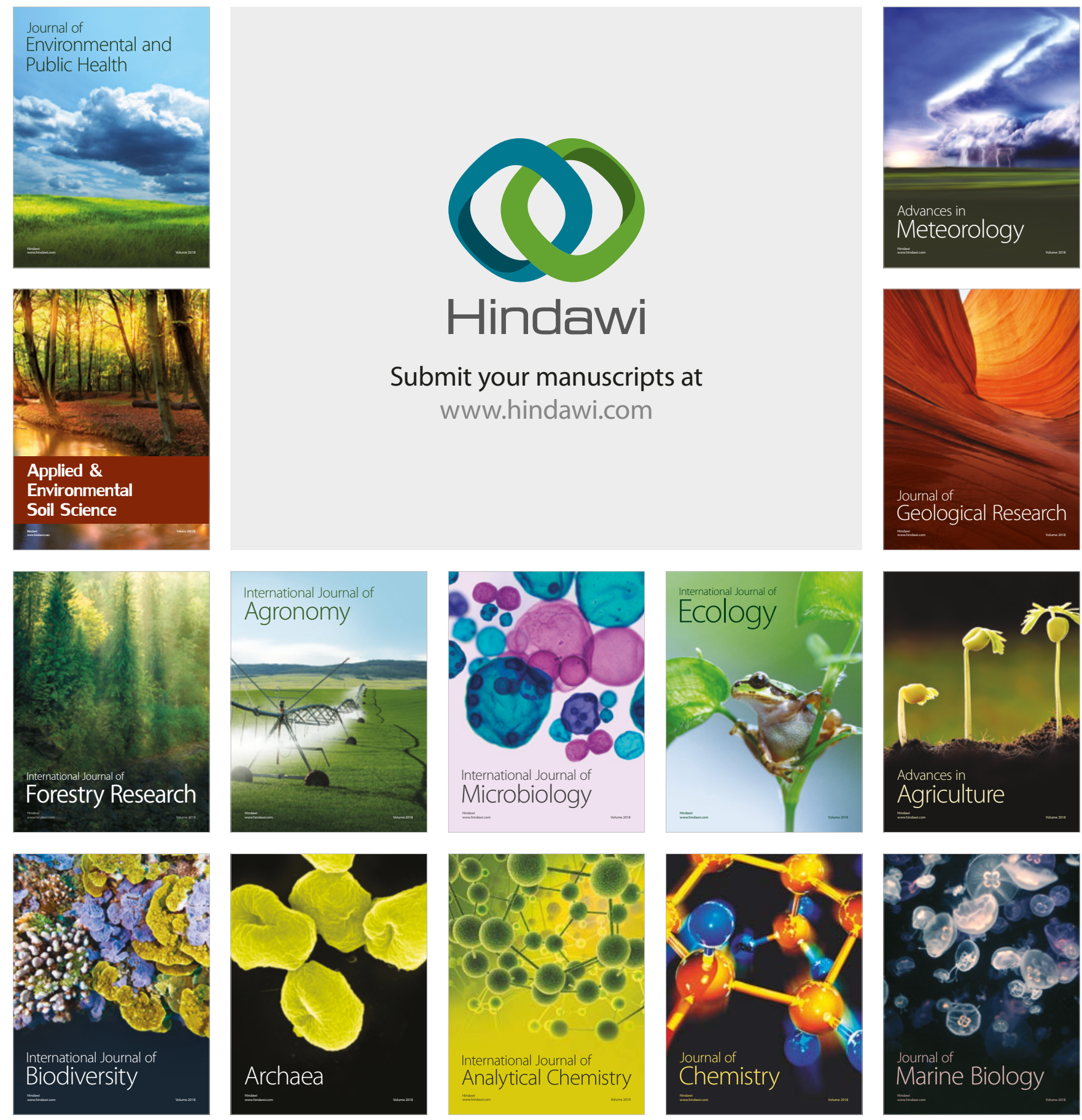